\title{
THE
}

\section{Rebuilding fish communities: the ghost of fisheries past and the virtue of patience}

Jeremy Collie

University of Rhode Island, jcollie@uri.edu

Marie-Joëlle Rochet

Richard Bell

University of Rhode Island

Follow this and additional works at: https://digitalcommons.uri.edu/gsofacpubs

Terms of Use

All rights reserved under copyright.

\section{Citation/Publisher Attribution}

Collie, J. , Rochet, M. and Bell, R. (2013), Rebuilding fish communities: the ghost of fisheries past and the virtue of patience. Ecological Applications, 23: 374-391. doi: 10.1890/12-0877.1

Available at: https://doi.org/10.1890/12-0877.1

This Article is brought to you for free and open access by the Graduate School of Oceanography at DigitalCommons@URI. It has been accepted for inclusion in Graduate School of Oceanography Faculty Publications by an authorized administrator of DigitalCommons@URI. For more information, please contact digitalcommons-group@uri.edu. 


\title{
Rebuilding fish communities: the ghost of fisheries past and the virtue of patience
}

\author{
Jeremy Collie, ${ }^{1,3}$ Marie-Joëlle Rochet, ${ }^{2}$ and Richard Bell ${ }^{1}$ \\ ${ }^{1}$ University of Rhode Island, Graduate School of Oceanography, Narragansett, Rhode Island 02882 USA \\ ${ }^{2}$ Institut Francais pour l'Exploitation de la Mer, B.P. 21105, 44311 Nantes CEDEX 03, France
}

\begin{abstract}
The ecosystem approach to management requires the status of individual species to be considered in a community context. We conducted a comparative ecosystem analysis of the Georges Bank and North Sea fish communities to determine the extent to which biological diversity is restored when fishing pressure is reduced. First, fishing mortality estimates were combined to quantify the community-level intensity and selectivity of fishing pressure. Second, standardized bottom-trawl survey data were used to investigate the temporal trends in community metrics. Third, a size-based, multispecies model (LeMans) was simulated to test the response of community metrics to both hypothetical and observed changes in fishing pressure in the two communities. These temperate North Atlantic fish communities have much in common, including a history of overfishing. In recent decades fishing pressure has been reduced, and some species have started to rebuild. The Georges Bank fishery has been more selective, and fishing pressure was reduced sooner. The two communities have similar levels of size diversity and biomass per unit area, but fundamentally different community structure. The North Sea is dominated by smaller species and has lower evenness than Georges Bank. These fundamental differences in community structure are not explained by recent fishing patterns. The multispecies model was able to predict the observed changes in community metrics better on Georges Bank, where rebuilding is more apparent than in the North Sea. Model simulations predicted hysteresis in rebuilding community metrics toward their unfished levels, particularly in the North Sea. Species in the community rebuild at different rates, with smaller prey species outpacing their large predators and overshooting their pre-exploitation abundances. This indirect effect of predator release delays the rebuilding of community structure and biodiversity. Therefore community rebuilding is not just the sum of single-species rebuilding plans. Management strategies that account for interspecific interactions will be needed to restore biodiversity and community structure.
\end{abstract}

Key words: biodiversity; fish community; Georges Bank; multispecies model; North Sea; restoration ecology; selective fishing.

\section{INTRODUCTION}

The conservation of biological diversity requires protection of threatened species and their natural habitats. In addition to the value of habitat and biodiversity per se, habitats and natural biodiversity are being restored to provide essential ecosystem functions and services (Palumbi et al. 2009) and resilience to climate change (Suding 2011). One of the commitments of the Convention on Biological Diversity is to rehabilitate and restore degraded ecosystems and to promote the recovery of threatened species (United Nations 1993). But even when management interventions are successful in protecting threatened species and habitats, they may not necessarily restore the historical biodiversity and ecological function of the community. In this paper we use long time series of fish community data, combined with a multispecies model, to investigate

Manuscript received 30 May 2012; accepted 11 September 2012. Corresponding Editor: K. Stokesbury.

${ }^{3}$ E-mail: jcollie@mail.uri.edu the process of rebuilding depleted fish communities. As individual species rebuild, are community structure and biodiversity restored?

Restoration ecology has developed as a science and practice over the last two decades (Palmer et al. 1997). One important issue when restoring an ecosystem is to define restoration end points (Palmer et al. 1997). It is generally agreed that every single species does not need to be re-established to historical levels; rather, the necessary pieces for "normal" structure and function need to be present; that is, fluctuations need to be bound within the normal range induced by environmental forcing and sustainable use (Parker and Wiens 2005). This definition makes the recovery goals fuzzy, and dependent on the type of ecosystem and/or impact.

Exploitation by fishing is now well known as one of the major human-induced stressors that affect marine ecosystems at many scales worldwide (Hall 1999, Gislason et al. 2000). Fishing affects biodiversity in various direct and indirect ways (National Research Council 1995). Even fishing at sustainable levels may 
incur considerable biodiversity loss compared with unfished conditions (Jennings 2007). The direct removal of target and nontarget species truncates the age composition of individual species and shifts the overall size structure of the community toward smaller individuals and smaller species. Bottom fisheries directly impact benthic communities that provide food and protection to demersal fish species (Hall 1999). Fishing alters the food web structure with indirect effects on interacting species. Therefore, rebuilding programs for individual stocks should also consider the restoration of ecosystem properties that may have been lost by overfishing.

Although ecosystem-based management has been promoted repeatedly over the last decades, rebuilding efforts seem to have focused on the recovery of individual species, not on restoring a complete community. Rebuilding world fisheries requires a triad of measures: reducing catch and effort, making fisheries more selective, and spatial management. These measures must be in combinations that are appropriate for each fishing jurisdiction (Worm et al. 2009). But what does rebuilding fisheries mean in an ecosystem perspective? Stock rebuilding has been examined in a community perspective, either addressing the community consequences of stock rebuilding (Andersen and Rice 2010), or the constraints on stock rebuilding imposed by the community and food web dynamics (Walters et al. 2008, Kempf et al. 2010). These studies do not yet address the issue of restoring the community itself. Rebuilding depleted stocks may be insufficient if the ecosystem service of providing food fish in a sustainable way requires ecosystem integrity (Murawski 2000).

Some results about marine community restoration after complete cessation of fishing are available from the assessment of marine protected areas (MPAs). Although most studies have focused on effects on specific species (Claudet et al. 2010), several studies have shown that MPAs generally result in increases in abundance, biomass, species richness, and diversity of some species groups, primarily large and/or target species, over a decadal scale (Claudet et al. 2006, Barrett et al. 2007). Similarly, the size of target species, and the size structure of the community, respond relatively quickly to fishery closure (Watson et al. 2009, Wilson et al. 2010). However, it seems more difficult to provide evidence of effects on nontarget groups or sizes (Guidetti et al. 2005, Kramer and Heck 2007), partly owing to the response delay, which may be long (McClanahan and Graham 2005, Stobart et al. 2009). In some cases, differential protection is required to restore some ecosystem components. For example, to restore mussel beds in a Mediterranean coastal ecosystem, partial protection, whereby fishing was limited and mussel exploitation prohibited, was more effective than total closure, for in the latter case rebuilding fish predator populations would graze mussel recruitment (Rius and Zabala 2008).

It is increasingly suggested that the selectivity of fishing, in addition to its intensity, shapes fishing effects on marine communities (Hall et al. 2000, Zhou et al. 2010). Recently a number of theoretical studies have addressed the question of the impact of fisheries selectivity on marine communities and biodiversity; model results suggest that both species selectivity and size selectivity interact with fishing intensity to determine the responses of communities to fishing (Andersen and Pedersen 2010, Rochet et al. 2011, Rochet and Benoît 2012). However, how community rebuilding depends on the selectively of exploitation has not been examined, to our knowledge. Moreover, there have been few empirical analyses of community responses to changes in fishing selectivity. Empirical studies of the effects of fishing on biodiversity require fishing selectivity to be characterized at the community level, which has seldom been done; average fishing mortality across species has been used as a metric of fishing intensity (Blanchard et al. 2005), but when it comes to size or species selectivity across several species, novel estimation methods are needed.

Understanding the effects of fishing on communities is complicated by other drivers and stressors. Shifts in productivity are known to affect fish communities on decadal time scales (Beaugrand 2004), and the more gradual effects of global warming are becoming increasingly apparent (Genner et al. 2004, Collie et al. 2008). Therefore, a study of changes in marine communities should incorporate the related environmental information. These drivers are temporally confounded and potentially interact with fishing, making the impacts of various pressures difficult to identify (Planque et al. 2010). A comparative ecosystem approach provides informative contrasts, reduces confounding, and provides a degree of "replication" (Murawski et al. 2010). In addition, community models can be used to isolate the effects of certain drivers.

Standardized bottom-trawl surveys are one of the few comprehensive sources of data to assess temporal changes in marine communities and assemblages. Trawl-survey data have been used to measure temporal changes within (Greenstreet and Hall 1996) and among ecosystems (Shackell et al. 2012). The strengths of research trawl surveys include relatively long duration with standardized sampling and species identification, including nontarget species, over many decades (Cotter et al. 2009). A weakness is that the trawls capture only a slice of the ecosystem, and even of the fish community (Jouffre et al. 2010). Any analysis of these data, and especially comparisons between surveys, must keep in mind the selectivity of bottom trawls.

This study examines in detail the dynamics of the North Sea and Georges Bank fish communities, which have been heavily exploited but experienced decreasing fishing pressure in the most recent decade. These two shelf-sea ecosystems have much in common, including shared and congeneric species, making them good candidates for comparative analysis. On the other hand, these ecosystems differ in community composition 
TABle 1. Comparison of main features of the Georges Bank and North Sea ecosystems.

\begin{tabular}{|c|c|c|c|}
\hline Feature & Georges Bank & North Sea & Source(s) \\
\hline Area $\left(\mathrm{km}^{2}\right)$ & 43000 & 575000 & Link et al. (2006), Eisma (1987) \\
\hline Average depth (m) & 50 & 93 & Sissenwine et al. (1984), Eisma (1987) \\
\hline Water temperature range $\left({ }^{\circ} \mathrm{C}\right)$ & $5-15$ & $6-17$ & $\begin{array}{l}\text { Ecosystem Assessment Program (2009), } \\
\text { Eisma (1987) }\end{array}$ \\
\hline Primary production $\left(\mathrm{g} \mathrm{C} \cdot \mathrm{m}^{-2} \cdot \mathrm{yr}^{-1}\right)$ & 330 & 212 & Steele et al. (2007), Heath and Beare (2008) \\
\hline Secondary producer production $\left(\mathrm{g} \mathrm{C} \cdot \mathrm{m}^{-2} \cdot \mathrm{yr}^{-1}\right)$ & 38 & 45 & Steele et al. (2007), Heath and Beare (2008) \\
\hline Total fish biomass $\left(\mathrm{Mg} / \mathrm{km}^{2}\right)$ & 29 & 19 & Link et al. (2011) \\
\hline Total fishery landings $\left(\mathrm{Mg} \cdot \mathrm{km}^{-2} \cdot \mathrm{yr}^{-1}\right)$ & $0.2-8.3$ & $1.6-7.0$ & this study \\
\hline
\end{tabular}

Note: The SI unit $\mathrm{Mg}=10^{6} \mathrm{~g}=1$ metric ton.

(Greenstreet and Hall 1996, Daan et al. 2005, Steele et al. 2007, Auster and Link 2009), the changes in fishing regulations and fishing pressure (Fogarty and Murawski 1998, ICES 2008), and shifts in the marine environment (Beaugrand 2004, Perry et al. 2005, Nye et al. 2009). To determine the main drivers of community change, we develop measures of overall fishing mortality and the degree of species and size selection at the community level from stock assessments. We also compile the main changes in the physical environment and ecosystem, which could, in turn, influence the food web. Based on this information, we identify time periods with major changes in both fishing and environmental drivers. Then we use trawl-survey data from the North Sea and Georges Bank to examine the changes in community metrics (including biomass and abundance, diversity and size-structure metrics) observed within each of these periods. Finally, we use a multispecies, size-based model to calculate the expected changes in community metrics given the observed exploitation patterns in the North Sea and Georges Bank. The overall goal of our research is to determine whether and how community rebuilding occurs when conventional management measures are implemented to rebuild depleted stocks.

\section{Materials And Methods}

\section{Study areas}

Georges Bank and the North Sea are both temperate shelf-sea ecosystems in the North Atlantic with some common features and other characteristics that differ (Table 1). Georges Bank is a submarine plateau in the northwest Atlantic, with shallow depths that promote strong benthic-pelagic coupling (Fig. 1). It is an open ecosystem, surrounded by the Gulf of Maine, the Scotian Shelf, the northwest Atlantic slope, and the southern New England continental shelf. A clockwise circulation pattern is more pronounced in summer, when the retention time of water on the bank is about five months (Sissenwine et al. 1984). Georges Bank supports discrete stocks of demersal fish species (e.g., cod (Gadus morhua), haddock (Melanogrammus aeglefi$n u s$ ), and flounder) and is also frequented by seasonal migrants (e.g., pelagics and elasmobranchs).

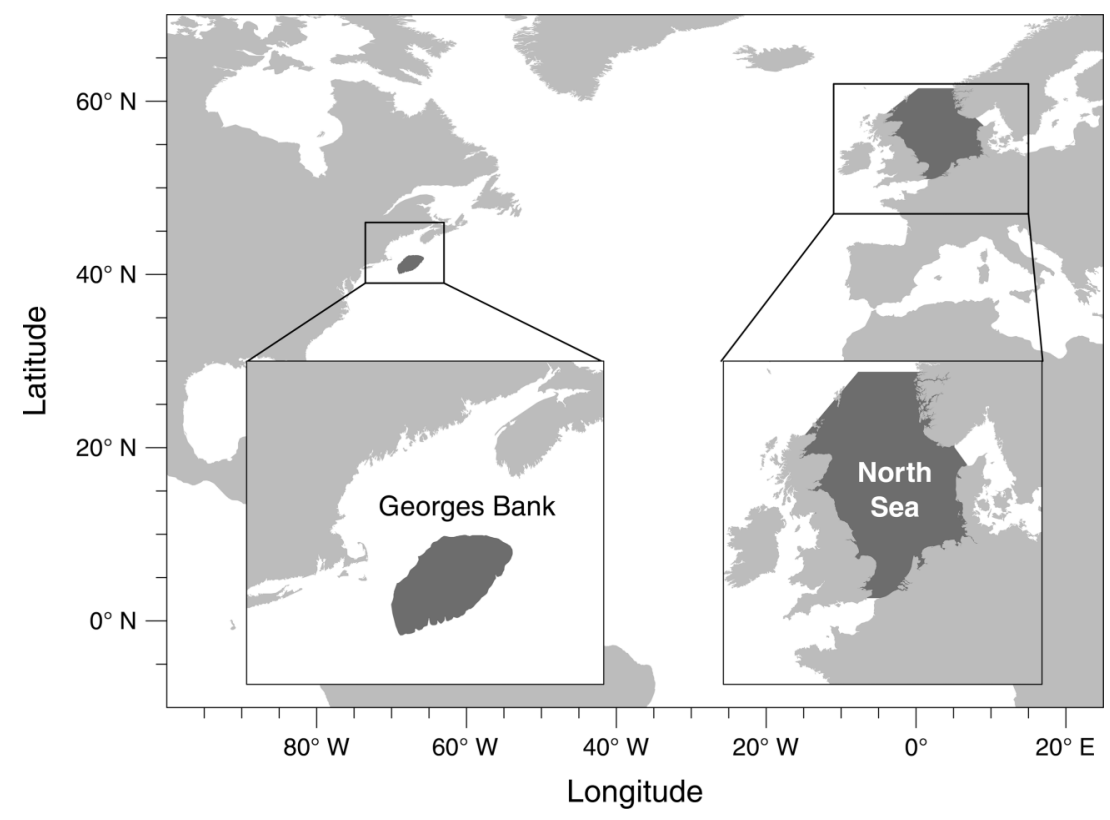

FIG. 1. Map of the North Atlantic with insets showing Georges Bank and the North Sea. 
The North Sea is a semi-enclosed marginal sea in the northeast Atlantic (Fig. 1). The North Sea communicates with the Norwegian Sea to the north, the Skagerrak to the east and the English Channel on the southeast. The water circulation through the North Sea is generally anticlockwise, with water entering in the north and exiting through the Norwegian Trench along the coast of Norway. This gyre is driven mainly by wind forcing and shows large seasonal and interannual variability (Eisma 1987). North Sea fish production is more dependent on zooplankton than on benthos (Heath 2005). Most of the important fish species reside year round in the North Sea, except seasonal migrants, such as blue whiting (Micromesistius poutassou), mackerel (Scomber scombrus), and horse mackerel (Trachurus trachurus).

The main drivers of community dynamics on Georges Bank and in the North Sea were compiled from the literature (see Appendices A and B). We focus primarily on the period 1960-2009 during which fish abundance data are available. On Georges Bank the important fishery management measures were listed by Fogarty and Murawski (1998). Important changes in the marine ecosystem are described in the ecosystem assessment report for the northeast U.S. shelf large marine ecosystem (Ecosystem Assessment Program 2009). Information on North Sea fisheries was taken from the OSPAR Commission (2000); important management measures during the last decade are listed in ICES (2008). Environmental drivers in the North Sea were identified by Kirby et al. (2007) and other references. On the basis of the primary fishery and environmental drivers we identified temporal stanzas for both Georges Bank and the North Sea, during which corresponding changes in the fish community would be expected.

\section{Fishing selectivity at the community level}

Measuring fishing pressure at the community level is difficult because it involves averaging across species and fleets. We derived our measures of fishing selectivity and intensity from fishing mortality estimates available from stock assessments. Obviously the assessed stocks are only a small part of the community components that actually bear the fishing pressure: several target stocks are not assessed; many other species are taken as bycatch, and/or are affected indirectly by fishinginduced changes in the ecosystem (Rochet et al., in press). Although our fishing pressure metrics are likely to be biased, they may still serve the double purpose of reflecting the temporal changes in overall fishing intensity and selectivity, and allowing a comparison of their magnitude across the two study areas. We measure selectivity as the variability of fishing mortality across species or length classes: fishing is selective when there are contrasts between species (or length classes), resulting in a large range and variance in fishing mortality rate $F$. A nonselective fishing pressure would be an equal $F$ across all species or length classes, with a null range or variance.

Average fishing mortality over fully recruited ages $\left(\bar{F}_{s}\right)$ was calculated by species and year to investigate overall fishing mortality and species selection. The mean and standard deviation of $\bar{F}$ across species within years were used as measures of overall fishing intensity and species selectivity, respectively. These calculations were performed with all species for which we could find agestructured stock assessments over a consistent time period: cod, haddock, mackerel, summer flounder (Paralichthys dentatus), winter flounder (Pseudopleuronectes americanus), witch flounder (Glyptocephalus cynoglossus), and yellowtail flounder (Limanda ferruginea) on Georges Bank; and cod, haddock, herring (Clupea harengus), plaice (Pleuronectes platessa), saithe (Pollachius virens), sand eel (Ammodytes spp.), sole (Solea solea), and whiting (Merlangius merlangus) in the North Sea.

Mean fishing mortality across species by length class was calculated to measure length selectivity. Estimates of fishing mortality $(F)$ by age for assessed species were converted to $F$ by length with growth curves for each species. To calculate the time spent in each length class, we used formulas from Jones' length cohort analysis:

$$
\tau\left(l_{1} l_{\mathrm{u}}\right)=\frac{1}{k} \ln \frac{L_{\infty}-l_{1}}{L_{\infty}-l_{\mathrm{u}}}
$$

where $\tau\left(l_{1} l_{\mathrm{u}}\right)$ is the time to grow from the lower $\left(l_{1}\right)$ to the upper $\left(l_{\mathrm{u}}\right)$ end of the length class, $k$ is the Brody growth coefficient, and $L_{\infty}$ is the asymptotic length (Quinn and Deriso 1999). The $F$ for each length class was calculated as a weighted average of the $F$-at-age falling within that length class, where the weights are based on the proportion of each age class within the length interval, calculated with Eq. 1. Likewise the numbers at age from the stock assessments were converted to numbers at length $N_{s, l}$ with a length-age key that contained the proportions by length in each age class. Once the $F$ and $N$ at length $l$ were available for each species $s$ they were combined into the weighted community average by

$$
\bar{F}_{1}=\frac{\sum_{s} N_{s, 1} F_{s, 1}}{\sum_{s} N_{s, 1}} .
$$

The standard deviation of $\bar{F}_{1}$ across lengths within threeyear blocks of time was used as the measure of length selectivity.

\section{Bottom-trawl surveys}

Observed changes in the community metrics were calculated from bottom-trawl data (see Plate 1). Georges Bank data are from the Northeast Fisheries Science Center fall bottom trawl survey. For the years included in this study (1963-2007) this survey used a No. 36 Yankee trawl with a $1.25-\mathrm{cm}$ liner. We used the data from 11 strata on Georges Bank, which together had 
$\sim 60$ stations each year. We used the stratified mean abundance and biomass by species, classified by $5-\mathrm{cm}$ length groups. Data for the North Sea are from quarter one of the International Bottom Trawl Survey (IBTS), which is conducted with a standardized GOV trawl with 2-cm mesh in the cod end (ICES 1996). The survey covers the entire North Sea, with 211 to 362 stations each year. We used the abundance data by species for the period 1982-2009, aggregated by 5 -cm length classes, during which a consistent sampling design and effort were deployed throughout the study area. Earlier years of IBTS, or earlier bottom trawl surveys in the North Sea, were not included because different survey designs, sampling gears, or season might significantly affect the metrics and confuse the studied effects. Biomass was estimated from abundance with length-mass relationships for each species. To facilitate comparisons, both the North Sea and Georges Bank data were standardized as per square kilometer. The data were not corrected for catchability, because the catchability conversions are uncertain and not available for all species (Fraser et al. 2007).

Rare species, for which high sampling variability would dominate their abundance patterns and which would make negligible contributions to most community metrics, were excluded. The mean abundance of each species over the survey time frame was plotted against persistence: the number of years the species was observed in the survey (Genner et al. 2004). A thirdorder polynomial was fit to these data and the inflection point calculated. We retained species to the right of the inflection point, which corresponds to high persistence and abundance. A second criterion was that the aggregate abundance of the selected species should account for $>99 \%$ of the total abundance. Invertebrate species were only recorded in the IBTS survey during the most recent 10 years, and were therefore not used in this study. On Georges Bank we selected 46 species with persistence above the inflection point (24 years) of the abundance-persistence plot; these 46 species constituted $99.3 \%$ of the overall abundance. Because the North Sea has a shorter time series with more stations, which translates to higher persistence, we applied a third filter to the North Sea only, selecting those species with mean density $>1$ individual $/ \mathrm{km}^{2}$, and persistence $>12$ years. For the North Sea, this resulted in 48 species, which accounted for $99.9 \%$ of the total abundance; we extended this list to include cuckoo ray (Leucoraja naevus), which does not meet the density criterion (average density $=0.15$ individual $/ \mathrm{km}^{2}$ ), but was included in the multispecies model (see species lists in Appendix C).

\section{Community metrics}

The trawl-survey data were used to calculate a suite of community metrics related to the distribution of individuals among species and size classes, which are expected to reflect fishing impacts (Rochet and Trenkel
2003). The response metrics include total abundance, mean length in the community, total biomass, and mean mass in the community. Each species was classified as commercial or noncommercial, and the proportional abundance of noncommercial species was calculated each year. Geometric mean abundance across species was calculated relative to the first year of the survey; this metric indicates whether several species are increasing/ decreasing at the same time (Rochet et al. 2010).

We do not consider species richness here because the measures of richness depend on the geographic extent of the survey, the sampling intensity, and the consistency in identifying and naming rare species. The two diversity metrics we calculated are both based on Simpson's diversity, $D$, which measures the probability that two individuals chosen at random belong to different species. Simpson's reciprocal evenness is $1 /(D S)$, where $S$ is the number of species; this index is independent of richness. Size diversity, $\Sigma$, is another extension of Simpson's diversity based on the distribution of individuals across size classes (Rochet and Benoît 2012). Size diversity is the average size difference between two individuals chosen at random from the community.

Total catch was calculated based on landing statistics. Georges Bank landings data were obtained from the Commercial Fisheries Database (Northeast Fisheries Science Center 2010). North Sea landings data were downloaded from the ICES catch statistics web site in January 2011 (available online). ${ }^{4}$ All landings from the North Sea were combined, that is Division IV (IVa, b, c, or IV nonspecified); Kattegat and Skagerrak were excluded.

This set of community metrics was compared between Georges Bank and the North Sea. We tested for linear trends in the metrics over the entire time series and during the temporal stanzas identified above: reported trends are those significant at $\alpha=0.05$. Significant trends in the community metrics were then interpreted with respect to model-based predictions of responses to changes in fishing intensity and selectivity.

\section{Multispecies length-based model}

To better understand how changes in fishing pressure and selectivity affect the community metrics, we used the length-based model LeMans, which simulates the dynamics of 21 species, divided into $10-\mathrm{cm}$ length categories (Hall et al. 2006). Fishing, predation, and residual natural mortality are all functions of length. All fished species are subject to the same fishing mortality rate. Because LeMans does not include food-dependent growth, it was not intended to investigate bottom-up propagation, but instead, top-down propagation through the community by predation. LeMans has been parameterized for Georges Bank and the North Sea and calibrated to match several metrics of each fish

\footnotetext{
${ }^{4}$ http://www.ices.dk/fish/CATChSTATISTICS.asp
} 
TABLE 2. Changes in major drivers of the North Sea and Georges Bank fish communities over the time period when survey data are available (Georges Bank, 1963-2007; North Sea, 1983-2009).

\begin{tabular}{|c|c|c|c|c|c|c|}
\hline \multirow[b]{2}{*}{ Driver } & \multicolumn{3}{|c|}{ Georges Bank } & \multicolumn{3}{|c|}{ North Sea } \\
\hline & 1963-1981 & 1982-1995 & 1996-2007 & 1983-1987 & $1988-2000$ & 2001-2009 \\
\hline Temperature & cool & variable & warm & cool & increasing & warm \\
\hline Phytoplankton & low & steady & decreasing & average & high & low \\
\hline Fishing effort & high & high/steady & decreasing & high & high/steady & decreasing \\
\hline Size selectivity & $\begin{array}{l}\text { toward larger } \\
\text { sizes }\end{array}$ & $\begin{array}{l}\text { toward larger } \\
\text { sizes }\end{array}$ & steady & $\begin{array}{l}\text { toward smaller } \\
\text { sizes }\end{array}$ & $\begin{array}{l}\text { toward larger } \\
\text { sizes }\end{array}$ & $\begin{array}{l}\text { toward intermediate } \\
\text { sizes }\end{array}$ \\
\hline Species selectivity & increasing & high & low & low & low & low \\
\hline
\end{tabular}

Note: See the appendices for detailed description and justification of each table entry.

community estimated from other sources: total biomass, rank biomass, size spectra, and predation mortality (Rochet et al. 2011). In most model runs, all species were started at their unfished levels, and a given fishing pattern was applied for 25 years, which was generally sufficient for most species to equilibrate. In this application, LeMans was used for four main purposes:

1) To predict the delay between a change in fishing mortality and community metrics as they move toward a new equilibrium. LeMans was started with each species at its unfished equilibrium; then a new level of fishing mortality $(F=1)$ was imposed and we tracked the rate of change of community metrics. With each species starting at its depleted equilibrium, the simulations were re-run with $F=0$ to see when the community metrics would recover to their unfished equilibrium levels. These trials used the key runs of LeMans for Georges Bank and the North Sea, in which fishing mortality was a logistic function of length. These simulations investigated how the community metrics respond to a strong on-off signal in fishing pressure.

2) To determine the sensitivity of the community metrics to the observed fishing patterns, we specified fishing intensity and size selectivity with the vectors of $F$ by length from each community calculated with Eq. 2. To obtain the greatest contrast, we used the $F$ at-length vectors from the first and last temporal stanzas with data available, as identified in the following paragraphs.

3) To test the extent to which the difference in community metrics between the two communities can be explained by their different exploitation patterns, we applied the exploitation pattern from the first stanza for the North Sea to Georges Bank and vice versa. To determine which species would not be fished when the exploitation patterns are switched, we found the closest taxonomic matches between the 21 species from each community. The most important change in species selection is that sand lance (Ammodytes spp.) is not fished on Georges Bank, but would become fished with the North Sea exploitation pattern.
4) To make qualitative predictions of changes in community metrics, we used the observed changes in fishing selectivity, combined with the results of the model simulations, and compared the results with the observed changes in survey-based community metrics and total landings. These trials tested the extent to which changes in community metrics can be explained by fishing as opposed to changes in the environment or other causes.

\section{RESULTS}

\section{Main drivers of community dynamics}

On Georges Bank there has been a general warming trend and increased productivity in recent decades (Table 2, Appendix A). At the same time there has been a shift from large phytoplankton and zooplankton species to smaller ones with higher turnover rates. This increase in water-column productivity is associated with a shift from benthic to pelagic fish production (Steele et al. 2007). Total Allowable Catch (TAC) quotas implemented in the 1970 s were replaced by minimum size limits in the 1980s (Appendix A). Amendments in the mid-1990s reduced fishing effort, expanded closed areas, and further increased mesh sizes. Because environmental change on Georges Bank has been more gradual than in the North Sea, the survey time period was divided into three temporal stanzas primarily according to changes in fisheries management (Table 2):

1) 1963-1981: management was primarily by ICNAF with low selectivity for species and size.

2) 1982-1995: there were no quotas and high fishing mortality, selectivity regulations.

3) 1996-2007: effective management measures were introduced and fishing mortality declined on most demersal species.

Environmental changes were more abrupt in the North Sea, where two regime shifts have been identified around 1988 and 1999-2000 (Table 2, Appendix B). Fisheries management in the North Sea was marked by the inception of the Common Fisheries Policy in 1983, when TACs were put in place, and its reform in 2002 with the development of long-term management plans. 


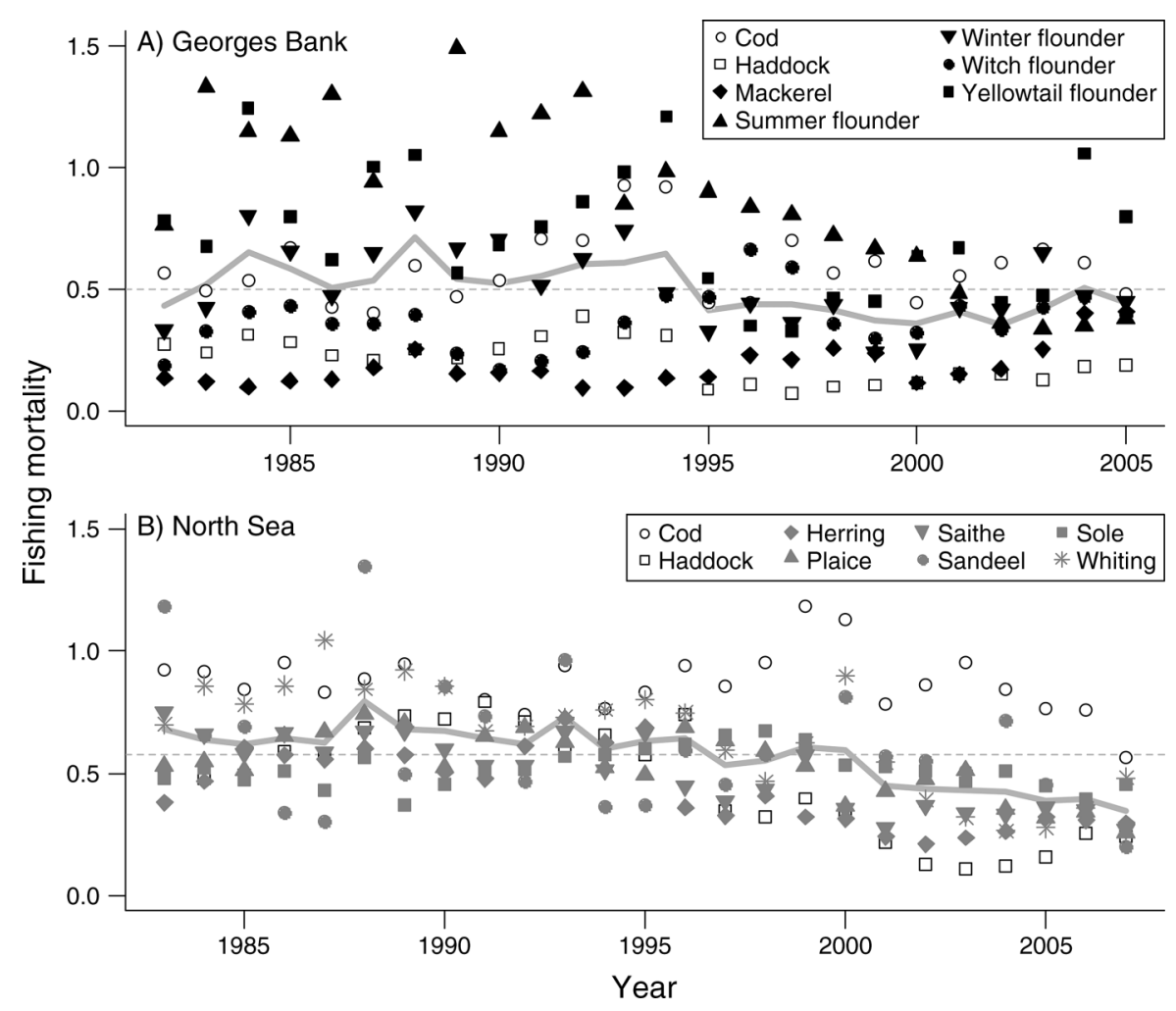

FIG. 2. Average fishing mortality-at-age $\left(\bar{F}_{s}\right)$ per species for $(\mathrm{A})$ seven assessed stocks on Georges Bank and (B) eight stocks in the North Sea. Bold lines show $\bar{F}_{s}$ averaged across stocks, and thin dashed lines show overall $\bar{F}_{s}$. Symbols identify the species.

In the North Sea the regime shifts were selected as limits for the temporal stanzas, the latter of which also coincided with a change in fisheries management (Table 2).

1) 1983-1987: there was high and increasing fishing pressure on many species, including small-sized individuals and species.

2) 1988-2000: fishing pressure remained high on all community components, and a climatologic regime shift occurred in 1988.

3) 2001-2009: another regime shift seems to have taken place in 2000; we also expect a decrease in fishing pressure, a diversification of target species and increase in size selectivity regulations.

\section{Fishing selectivity at the community level}

Fishing intensity on Georges Bank, as measured by average fishing mortality, remained steady from 1982 to 1995 and slightly decreased thereafter (Fig. 2A). Species selectivity, measured by the standard deviation of stockspecific average fishing mortality rates $\left(\bar{F}_{s}\right)$, remained quite constant until 1995 and then decreased (Fig. 3). Community fishing mortality increased with length and showed two peaks around 55 and $85 \mathrm{~cm}$ in the first stanza (Fig. 4A). Starting in 1996, fishing mortality on the intermediate sizes was reduced and community mortality became monotonically increasing with length up to the peak at $85 \mathrm{~cm}$. In the 2000s, fishing mortality was reduced on intermediate and large sizes but increased for the $30-40 \mathrm{~cm}$ size class. Length selectivity increased until 1995 as mesh restrictions were implemented, and then declined with the addition of nonselective regulations including effort reduction and closed areas (Fig. 3).

Mean levels of fishing mortality were slightly higher in the North Sea than on Georges Bank (Fig. 2A, B). Fishing intensity in the North Sea decreased continuously from 1988 to 2007 (Fig. 2B). The range of stock-

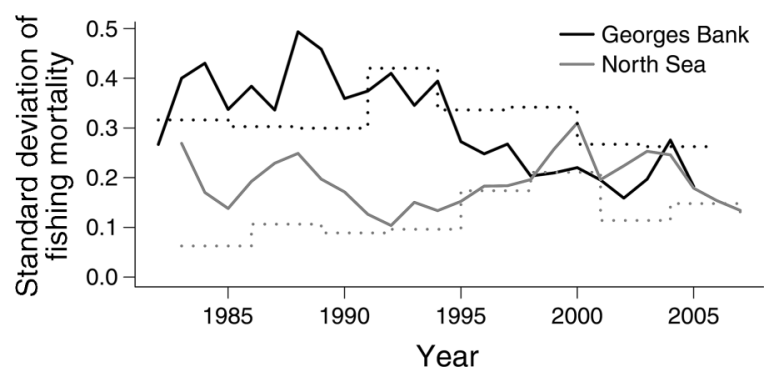

FIG. 3. Fishing selectivity as measured by the standard deviation of fishing mortality across species (solid lines) and across lengths (dotted lines). High standard deviations imply selective fisheries (the most targeted species and sizes incur fishing mortality at much higher rates than the least targeted ones). 


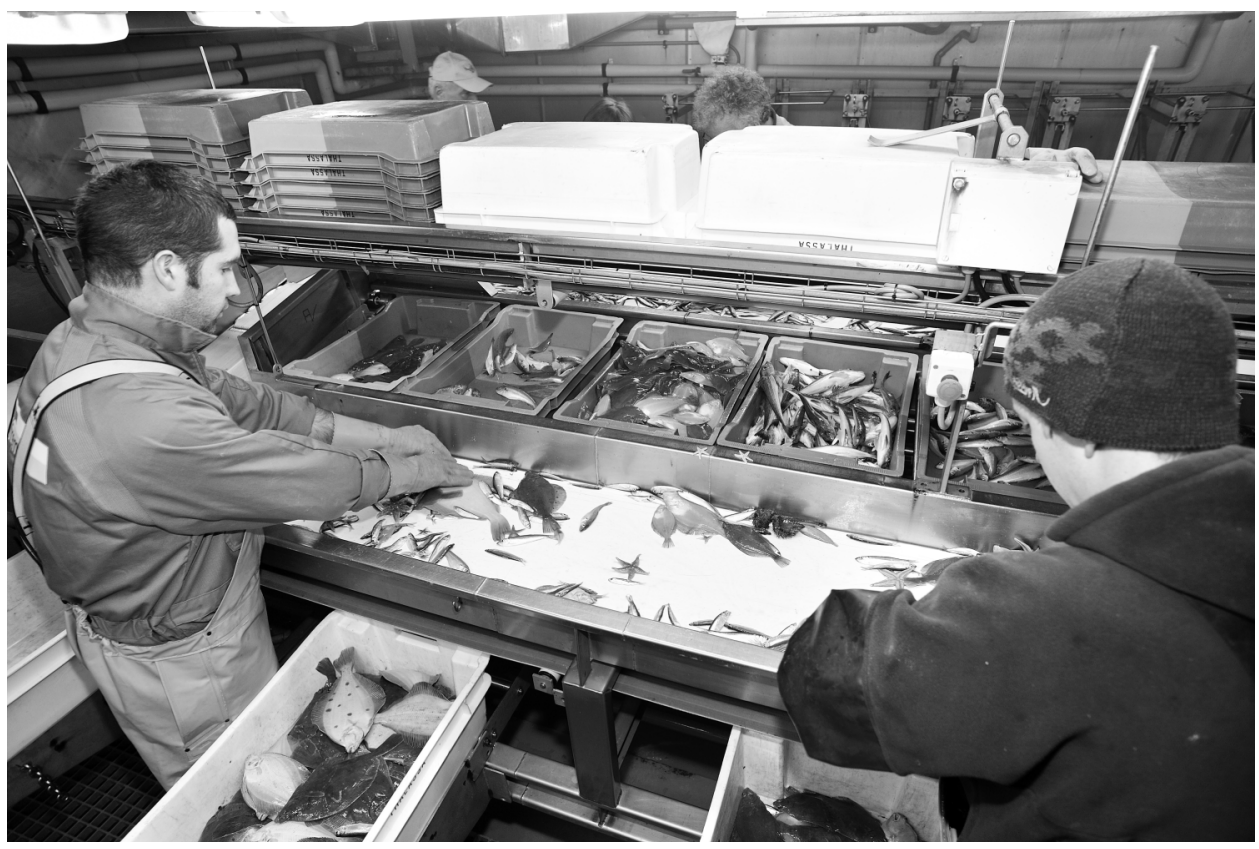

Plate 1. The North Sea International Bottom Trawl Survey. Scientists aboard the French research vessel Thalassa sort the catch from a trawl survey station. Photo credit: IFREMER, Olivier Dugornay.

specific $\bar{F}_{s}$ was much narrower than on Georges Bank and remained constant over time, such that species selectivity varied without trend (Fig. 3). Target lengths were smaller than on Georges Bank, with peaks in the community selection curve around 30 and $60 \mathrm{~cm}$ in the 1980s; the former (corresponding to the industrial fisheries) remained in place over the whole time period, while the latter slowly shifted towards larger sizes (Fig. 4B). After 2002 fishing mortality was reduced on all sizes except the 10-20 cm length class. Length selectivity increased toward larger lengths, but this increase ceased in the most recent years (Fig. 3).

\section{Community metrics}

Total abundance was 10 times higher in the North Sea than on Georges Bank, even when the data were standardized by area (Fig. 5A). In the North Sea, abundance increased during the second stanza and decreased during the most recent period. On Georges Bank, total abundance increased over the entire time period, but there were no significant changes during any of the stanzas. Total biomass was higher in the North Sea until 2000, but decreased steeply over the most recent time period, while biomass on Georges Bank increased over the whole time series with an acceleration over the most recent stanza; as a result, in the most recent years biomass was higher on Georges Bank (Fig. $5 \mathrm{~B})$. Mean length in the community was $\sim 20 \mathrm{~cm}$ higher on Georges Bank than in the North Sea (Fig. 5C). There were no significant time trends in mean length on Georges Bank, while mean length decreased over the two last time stanzas in the North Sea. The difference in mean length between the communities is amplified in mean mass (Fig. 5D). In the North Sea, mean trends in mass were similar to those in mean length, whereas on Georges Bank, there was a significant decline only during the middle period.

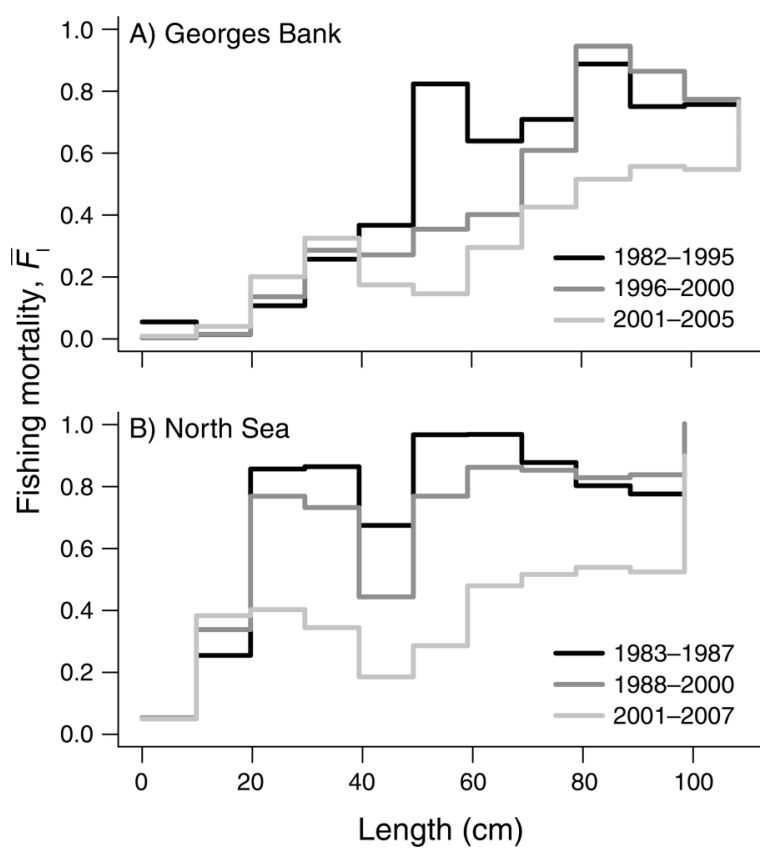

FIG. 4. Community fishing mortality by length $\left(\bar{F}_{1}\right)(\mathrm{A})$ on Georges Bank (seven stocks) and (B) in the North Sea (eight stocks) by blocks of years. 
A) Total abundance

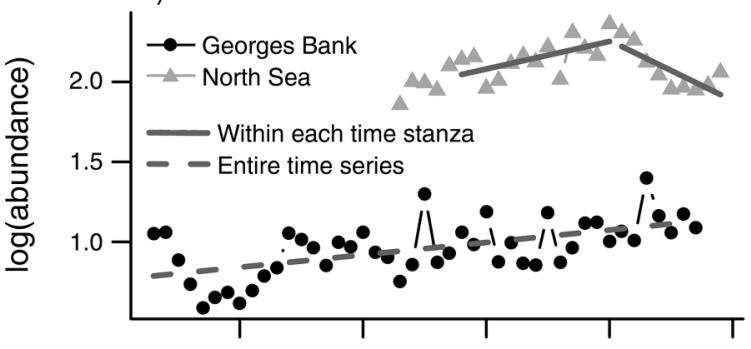

C) Mean length

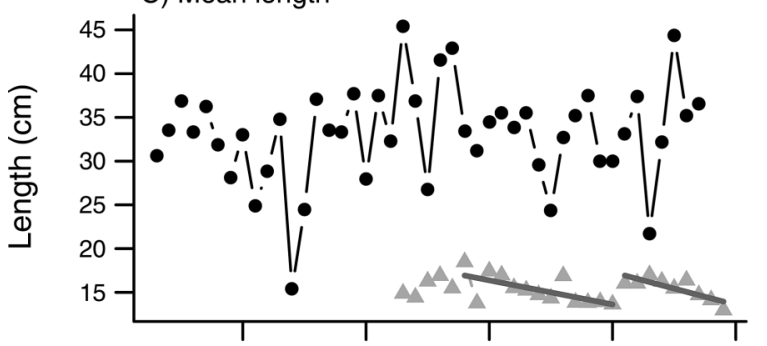

E) Geometric mean abundance

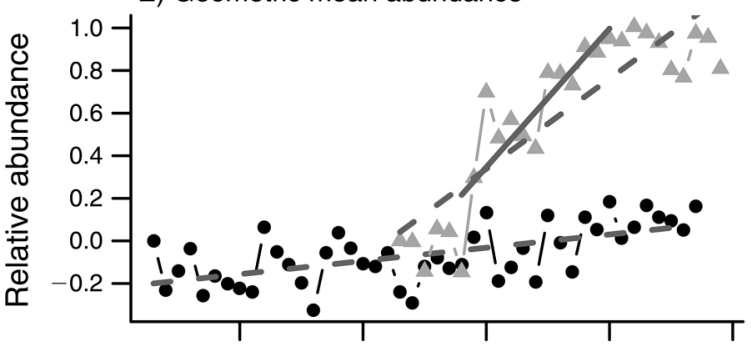

G) Reciprocal evenness

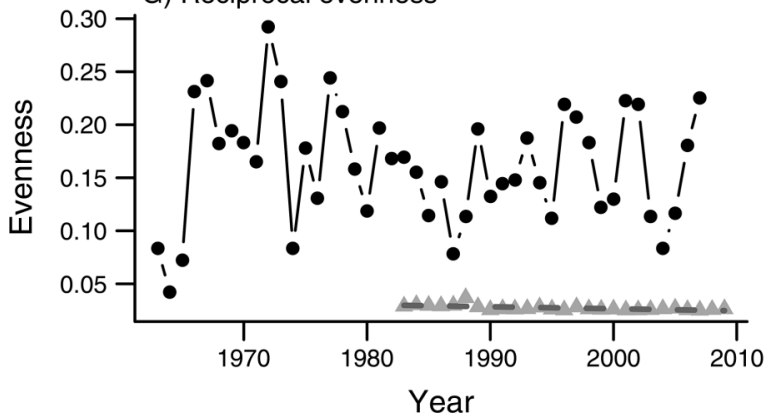

B) Total biomass

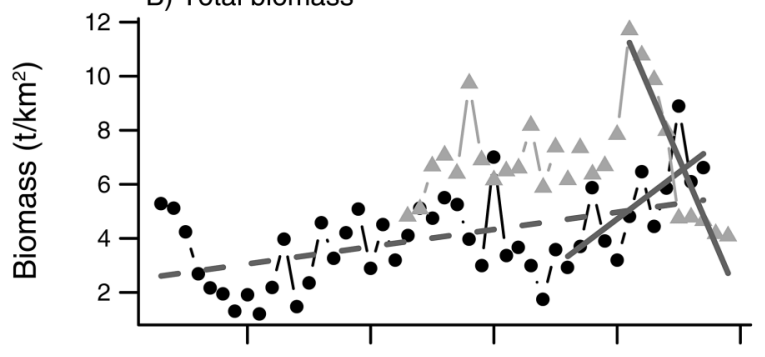

D) Mean mass

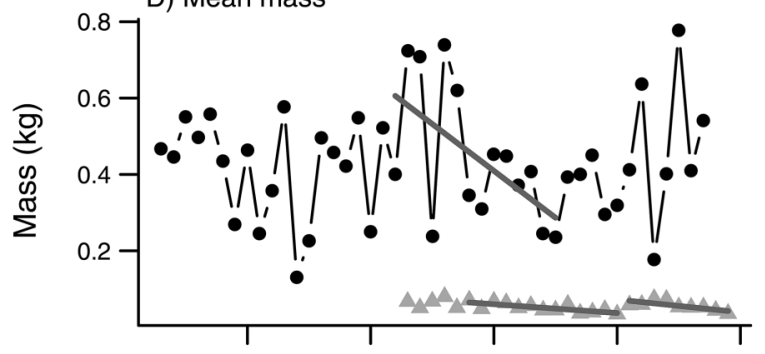

F) Noncommercial species

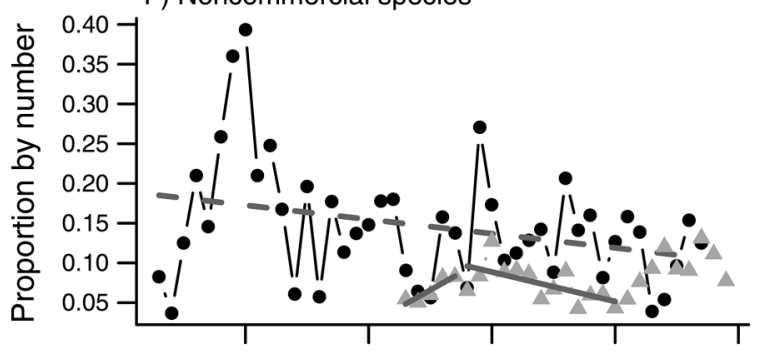

H) Size diversity

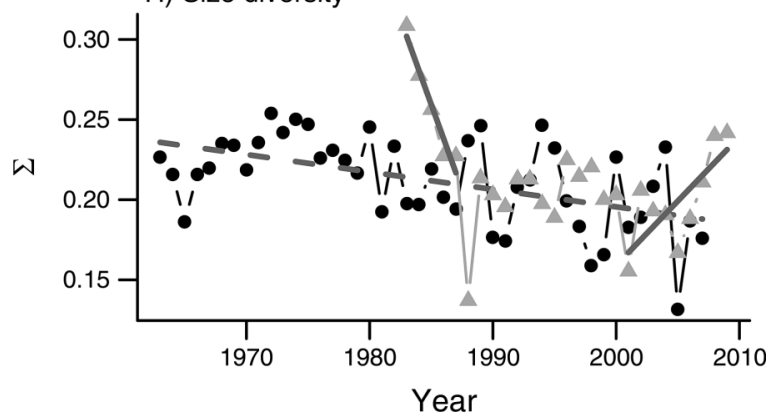

FIG. 5. Temporal changes in community metrics in the North Sea (light gray triangles) and on Georges Bank (black circles). Significant $(\alpha=0.05)$ temporal trends are indicated with thick solid lines within each time stanza and with thick broken lines for the entire time series.

Geometric mean abundance increased significantly in the North Sea, especially during the middle time period (Fig. 5E), which corresponds to increase in abundance of several species (27 out of 49 species with significant increasing trend, $\alpha<0.05)$. Geometric mean abundance also increased gradually on Georges Bank over the entire time period, with 18 out of 46 species with significant increasing trend. On Georges Bank more species were noncommercial than in the North Sea (16 of 46 against 15 of 49) and their contribution to total biomass was higher, so that the proportion of noncommercial species was higher on Georges Bank; it declined over the entire survey time period (Fig. 5F). Evenness was consistently higher on Georges Bank than in the North Sea, where it still decreased over the whole time period (Fig. 5G). Size diversity was roughly similar in the two areas during the 1990s (Fig. 5H). It consistently decreased on Georges Bank as the size spectrum became more bumpy (Fig. 6A). By contrast, size diversity decreased steeply in the North Sea over the first time 
stanza (Fig. $5 \mathrm{H}$ ) as the size spectrum became steeper; size diversity increased again over the most recent time stanza, with the loss of animals in all size classes making the size spectrum overall more regular (Fig. 6B).

The Georges Bank size spectrum is convex (upwards) with a lack of individuals in the smaller size classes and relatively more individuals in the intermediate size classes (Fig. 6A). Within size classes, many species contribute to the overall abundance, with substantial changes in species composition over time. During the most recent decades, the abundance of intermediatesized individuals increased to form distinct subpeaks, while abundance in the larger size classes declined. The subpeak in the 1980s was caused by an increase in spiny dogfish (Squalus acanthias); the ridge in the 1990s and 2000 s reflects an increase in haddock. In contrast, the North Sea size spectrum is much more regular, with more small and fewer intermediate-sized individuals (Fig. 6B). Within size classes, a few species dominated the overall biomass, and their relative abundance was less variable than on Georges Bank. In the North Sea there was little change over time, apart from a peak in large individuals that consisted primarily of cod over 1995-1999 and pollock (saithe) over 2000-2003.

\section{Community model results}

Most community metrics for Georges Bank responded within five years to a step in fishing pressure, be it an increase or decrease (Fig. 7). Total biomass was the most reactive metric and stabilized after two years of high fishing pressure, or recovered within five years to its unfished level when fishing was released. However, this constancy in total biomass concealed profound changes in the fish community. Although the metrics responded quite quickly to the removal of fishing pressure, all but total biomass reached levels intermediate between the unfished and exploited states. Compared with the unfished community, fish in the rebuilding community had low average mass, and species evenness was low. This is because not all species recovered when fishing was interrupted: some predators such as winter skate (Leucoraja ocellata), spiny dogfish, and pollock remained at a low level even after 25 years without fishing (results not shown); others such as little skate (Leucoraja erinacea) or white hake (Urophycis tenuis) started to recover only after 20 years, As a consequence, some species at lower trophic levels, such as herring, red hake (Urophycis chuss), or silver hake, had higher abundances than in the unfished state.

In general, the community metrics for the North Sea responded more slowly to changes in fishing pressure (Fig. 7) than for Georges Bank. Responses were apparent after five years, but most metrics continued to change, even up to 25 years. The metrics changed more slowly in the rebuilding scenario and none recovered to its unfished level. Mean mass and biomass increased slowly over 25 years but did not approach their unfished levels. Evenness declined slightly and was
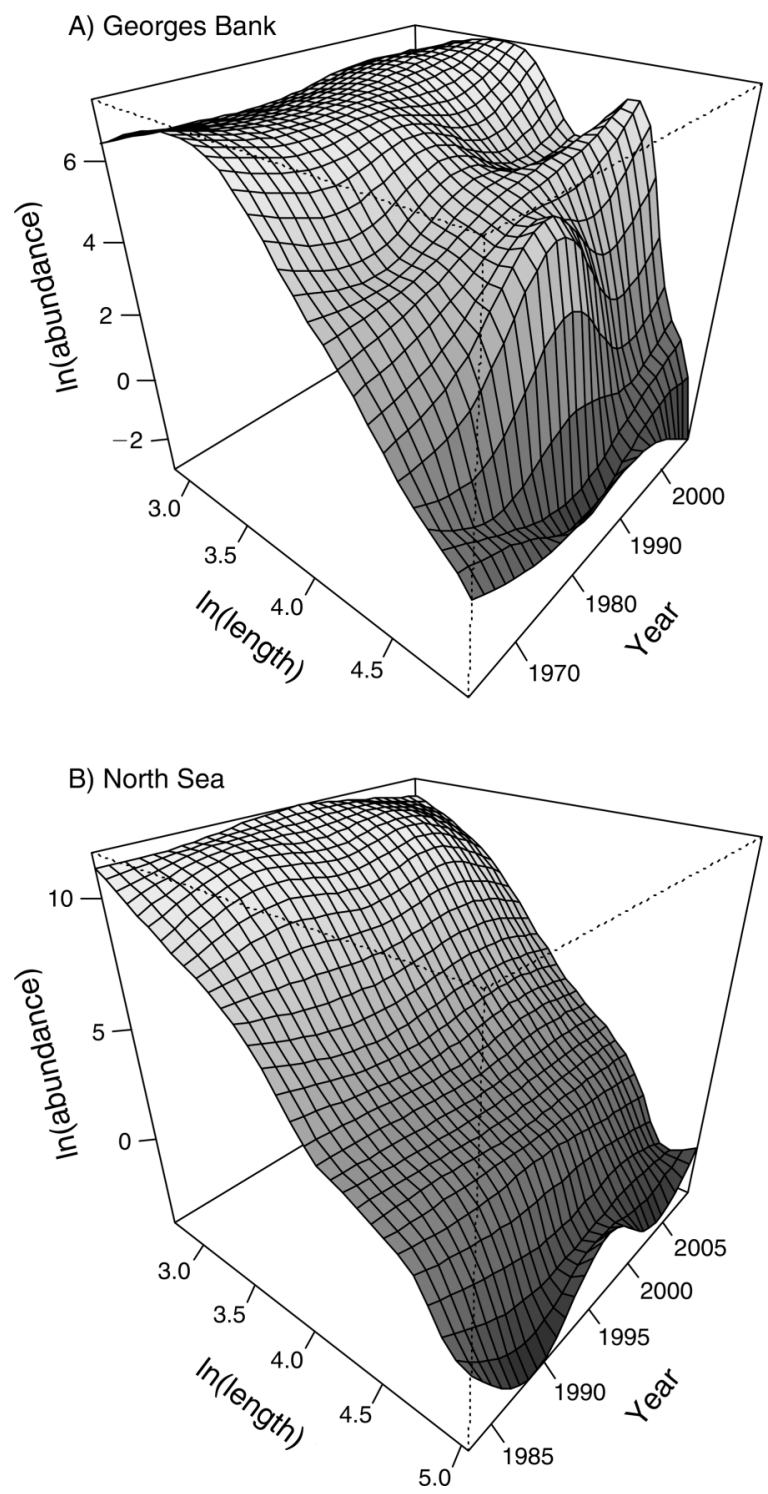

FIG. 6. Size spectra for (A) Georges Bank and (B) the North Sea, showing log-transformed abundance per surface area (numbers $/ \mathrm{km}^{2}$ ) as a function of log-transformed length (cm) through time, for lengths $\geq 15 \mathrm{~cm}$. Each surface was fitted with a generalized additive model.

lower at the end of the 25-year simulation than at the start. Only size diversity increased to a level approaching the unfished community. Most species (e.g., cod, haddock, monkfish [Lophius spp.], witch [Glyptocephalus cynoglossus]) recovered from depletion, but others did not (e.g., saithe, herring). The community structure in the rebuilding community was shifted toward more abundant smaller species compared with the unfished community.

When the length-based model was run with empirically derived fishing-mortality-at-length vectors corresponding with the first and last temporal stanzas, most of the metrics changed in the direction that would be 

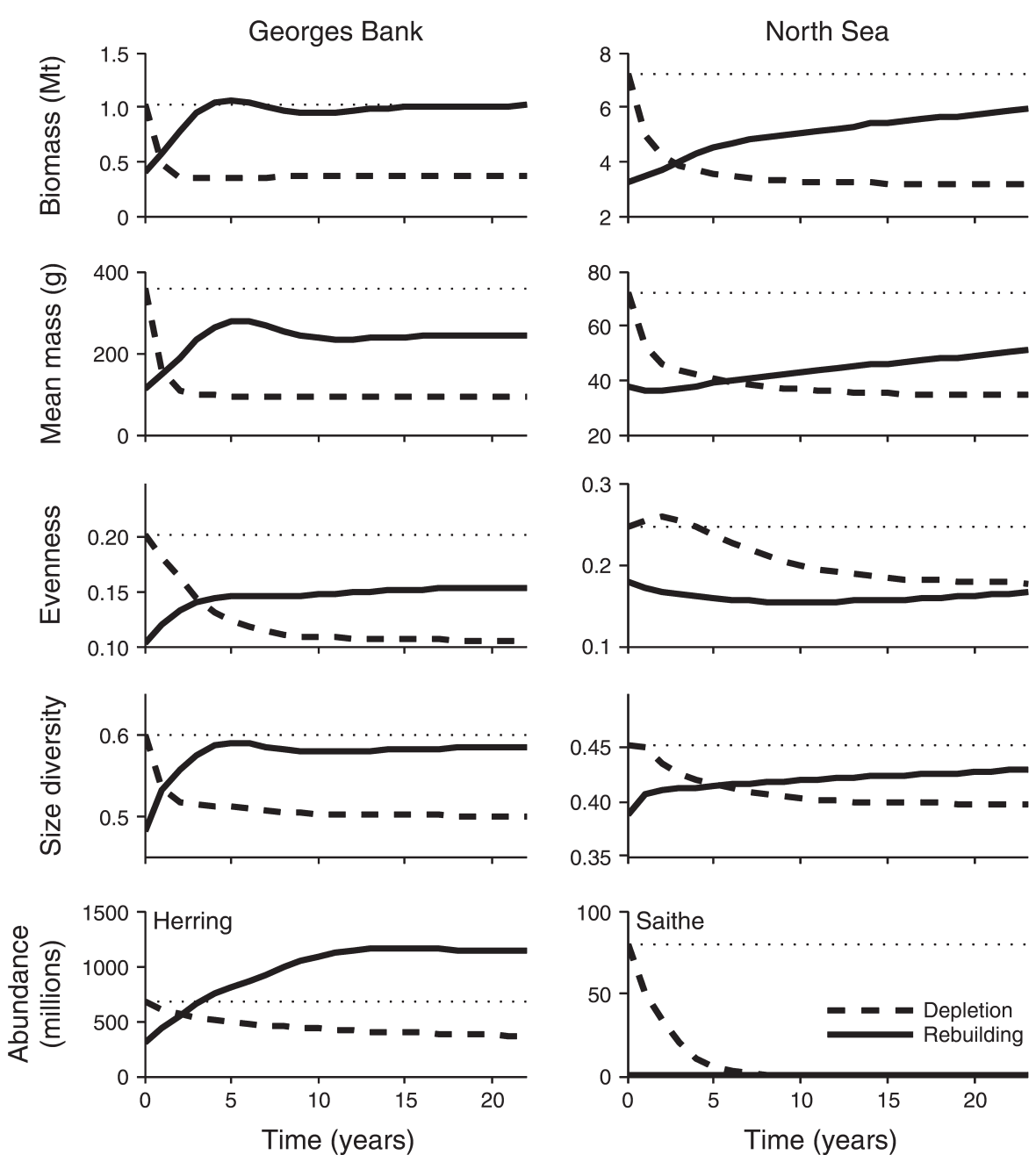

FIg. 7. Model simulation of the Georges Bank and North Sea community depletion and rebuilding. The dashed line shows depletion starting in year 0 from the unfished equilibrium with a high fishing mortality $(F=1)$ and low size selectivity; the solid line shows rebuilding from the resulting depleted state at year 0 and no fishing mortality $(F=0)$; the thin dotted line is the reference level (unfished community) for each metric.

expected with reduced fishing mortality (Fig. 8A, B). On Georges Bank, the main changes between the first and last stanzas were an overall reduction in fishing intensity and a reduction in size selectivity (Fig. 4A). All community metrics but one moved toward the reference level with no fishing; however the increases in mean length, noncommercial species, evenness, and size diversity were relatively small. The reduction in total catch reflects the reduction in fishing intensity, as most Georges Bank species were at sustainable abundance levels in the first time period. In the North Sea there was also a reduction in fishing pressure between the first and last temporal stanzas (Fig. 4B). All community metrics changed in the direction that would be expected with reduced fishing mortality (Fig. 8B). In this case total catch increased, as many of the species (e.g., sole, mackerel, whiting, haddock, and cod) recovered to levels that support sustainable catches. These simulations confirmed our expectations, based on Rochet et al. (2011), of how community metrics should change in response to changing exploitation patterns.

If the Georges Bank community is fished with the North Sea vector of $F$ by length (Fig. 8), does the Georges Bank metric (arrowhead) more closely resemble the corresponding metric for the North Sea (vertical broken line) than when Georges Bank is fished with Georges Bank values of $F$ (arrow tail)? The North Sea exploitation pattern is less selective with overall higher fishing mortality. Only three of eight metrics changed in the direction that would make Georges Bank more closely resemble the North Sea fish community (Fig. $8 \mathrm{C})$. Catch declined as the community was increasingly overfished. Total numbers on Georges Bank declined instead of increasing because sand lance was now fished. If Georges Bank is fished with the North Sea $F$ values, mean mass and mean length would increase instead of 
FIG. 8. Changes in community metrics with empirically derived fishing mortality by length $\left(\bar{F}_{l}\right)$. The left-hand panels compare the results of applying the $\bar{F}_{l}$ vectors from the first (arrow tails) and last (arrow heads) time stanzas. (A) Georges Bank and (B) North Sea. In these two cases the metrics are plotted relative to their unfished levels (broken lines), except for catch, which is normalized relative to maximum catch. The right-hand panels compare the results of applying the fishing patterns from the North Sea to the Georges Bank community. In panel $(\mathrm{C})$ the arrows point from the metric value with the Georges Bank fishing pattern to the value with the North Sea pattern, plotted relative to the metric value for the North Sea community. Panel (D) makes the same comparisons for the North Sea community fished with the Georges Bank exploitation pattern. The metric abbreviations are: $\Sigma$, size diversity; SRE, evenness; Ntot, total abundance; Btot, total biomass; PNC, proportion of noncommercial species; Lbar, mean length; Wbar, mean mass; and Gtot, geometric mean abundance.
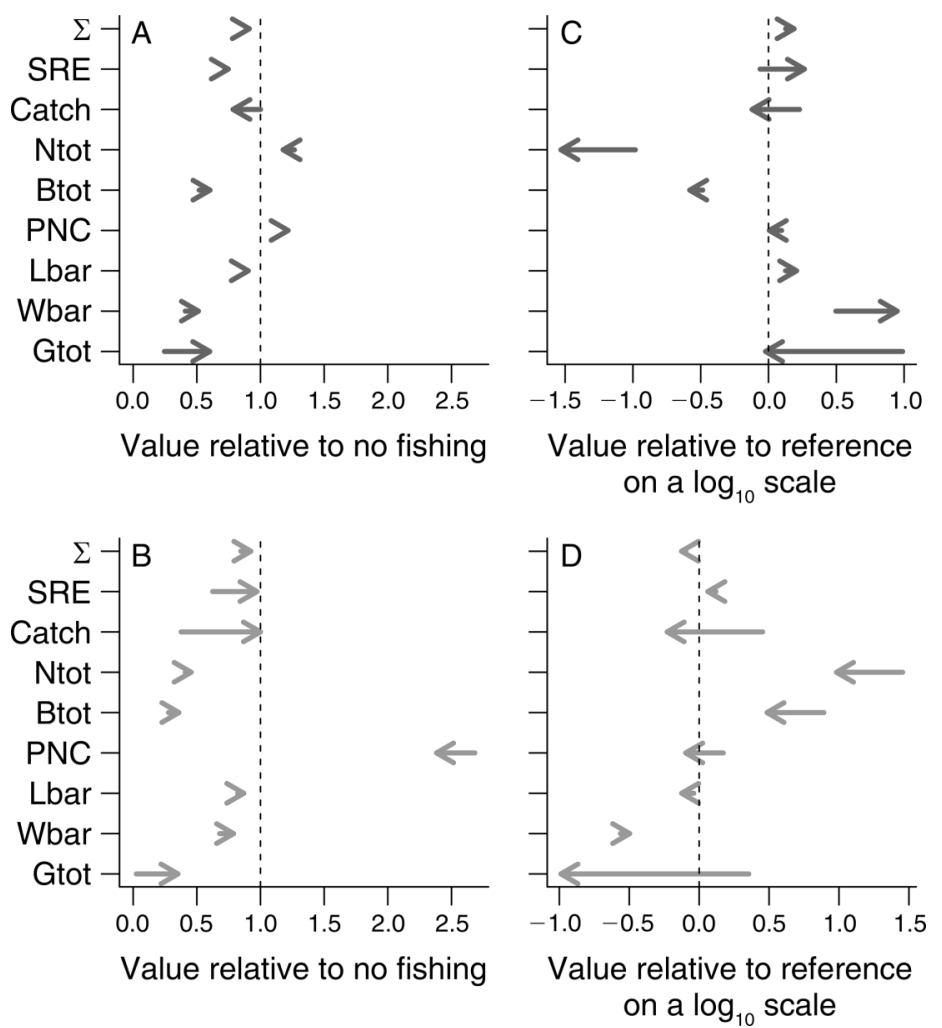

decrease, presumably because of reduced size selectivity. Evenness and size diversity would both increase, not decrease, because the North Sea fishing pattern is less selective.

If the North Sea community is fished with the Georges Bank fishing patterns for period one, the fishery would be more selective, with overall lower fishing mortality. Six of the metrics would move in the direction to make them more similar to those from Georges Bank, but three of the six would overshoot the Georges Bank value (Fig. 8D). Catch would decrease because fishing mortality would be higher on species and sizes available at low abundances. Total numbers and biomass would decrease, because of the indirect effect of more predators. Evenness and size diversity would both decrease because the Georges Bank fishing pattern is more selective.

In both communities, the aggregate fish metrics (total numbers, biomass, and catch) would all decrease when fishing pressure from one community was applied to the other, but for different reasons. The metrics related to biodiversity changed in the directions corresponding to the changes in selectivity, if not to their expected values. It was generally easier to make the North Sea community resemble Georges Bank than the opposite, the exception being the proportion of noncommercial species, which was higher on Georges Bank and became lower when fished with the North Sea values of $F$. These results reflect fundamental differences in the size and species composition of the two fish communities.

\section{Comparison of model predictions with observed community metrics}

On Georges Bank changes over the whole time period in five of nine metrics were consistent with the modelbased responses to changes in fishing pressure (both intensity and selectivity), but no recent change in metric trends ascribable to the most recent changes in fishing pressure could be detected (Table 3). By contrast, in the North Sea one single metric, geometric mean of abundances, responded to fishing pressure as expected over the whole time series (Table 3 ). Two trends over the most recent period (increasing size diversity and decreasing catch) matched the expectations from model results. The North Sea community seemed to be responding more on a short time scale to environmental changes. Total abundance seemed to follow the patterns in primary production; the increase in abundance over 1988-2000 affected primarily small-sized species and/or recruitment of large-sized species, so that total biomass did not increase and average size (mass and length) decreased. By contrast, after 2001, total abundance, biomass, and average size all decreased when primary production decreased (Table 3 ).

\section{Discussion}

We found that the management measures both on Georges Bank and in the North Sea actually resulted in changes in fishing intensity and selectivity at the community level. While these changes translated into 
TABLE 3. Summary of trends in community metrics and landings.

\begin{tabular}{|c|c|c|c|c|c|c|c|c|c|}
\hline Location and dates & Ntot & Btot & Lbar & Wbar & Gtot & $\mathrm{PNC}$ & SRE & $\Sigma$ & $\overline{\text { Catch }}$ \\
\hline \multicolumn{10}{|l|}{ Georges Bank period } \\
\hline $1963-1981$ & 0 & 0 & 0 & 0 & 0 & 0 & 0 & 0 & 0 \\
\hline $1982-1995$ & 0 & 0 & 0 & - & 0 & 0 & 0 & 0 & $-\dagger$ \\
\hline $1996-2007$ & 0 & + & 0 & 0 & 0 & 0 & 0 & 0 & - \\
\hline 1963-2007 & + & $+\dagger$ & $0 \dagger$ & 0 & $+\dagger$ & - & $0 \dagger$ & - & $-\dagger$ \\
\hline \multicolumn{10}{|l|}{ North Sea period } \\
\hline $1983-1987$ & 0 & 0 & 0 & 0 & 0 & + & 0 & - & + \\
\hline $1988-2000$ & + & 0 & - & - & + & - & 0 & 0 & - \\
\hline 2001-2009 & - & - & - & - & 0 & 0 & 0 & $+\dagger$ & $-\dagger$ \\
\hline $1983-2009$ & 0 & 0 & 0 & 0 & $+\dagger$ & 0 & - & 0 & - \\
\hline
\end{tabular}

Notes: The metrics are: Ntot, total numbers; Gtot, geometric mean abundance; Btot, total biomass; Wbar, mean mass in the community; PNC, proportion of noncommercial species; SRE, Simpson reciprocal evenness; $\Sigma$, size diversity. Key to symbols: + , increase; - , decrease; 0 , no significant change $(\alpha=0.05)$.

$\dagger$ Trends in agreement with expectations from model simulations (Fig. 8) $(P<0.05)$.

the rebuilding of several stocks in both ecosystems, we found evidence of community rebuilding on Georges Bank only. This result was not completely consistent with model-based expectations, although we predicted a slower rebuilding in the North Sea. The difference in rebuilding rates may be ascribable to differences in the changes in fishing pressures, in environmental effects, in the communities themselves, or a combination. Rebuilding individual populations does not guarantee community rebuilding, which may occur more slowly, if at all. These main findings are discussed in more detail in the following sections.

\section{Changes in fishing pressure at the community level}

The management measures seem to have translated relatively well into fishing pressure on the community, at least on Georges Bank. From 1982 to 1995, fishery management in that area relied on technical measures only; no output control was in place. Consequently, selectivity and community-level fishing mortality were both high. The policy change in 1995-1996 resulted in a conspicuous drop in fishing mortality. Fishing pressure measured by an exploitation index (landings-to-biomass ratio) calculated for much longer species lists were also found to have declined over the period 1970-2007 (Shackell et al. 2012; Rochet et al., in press), but more gradually, suggesting that the mid 1990s management measures affected primarily the main target species. At the same time, species selectivity decreased, probably as fishermen targeted other species to compensate for limited catch of their traditional targets; length selectivity slightly decreased as well, perhaps partly as a consequence of the change in target species, as the new targets were smaller.

By contrast, management in the North Sea has been based on TACs since its inception in 1983, but encountered enforcement difficulties, so that the decrease in fishing mortality has been more gradual, and accelerated only over the last decade with the second revision of the European Union Common Fisheries Policy in 2002. The decline in fishing intensity, including its recent acceleration, is consistent with another index of community fishing mortality rate, estimated by the simple average across seven stocks of fishing mortality standardized by their precautionary reference points (Greenstreet et al. 2011). Species and size selectivity were both much lower in the North Sea than on Georges Bank. Our estimates suggest that fishing mortality by length in the North Sea increases steeply for lengths as small as $20 \mathrm{~cm}$, consistent with the findings of a study that combined fish abundance maps, international effort data, and a catchability model to estimate fishing mortality for various groups of target and nontarget fish (Piet et al. 2009). In summary, we found contrasting patterns of change in the fishing pressure at the community level: both communities experienced a decrease in fishing intensity, which was larger but more gradual in the North Sea. Therefore we expect to see changes in both communities toward the rebuilding direction. However, selectivity changed significantly on Georges Bank only, where it decreased toward more species and a wider size range, possibly mitigating the response to decreased fishing intensity.

\section{Do changes in fishing pressure result in stock rebuilding?}

Looking at the subset of assessed stocks, let us examine to what extent rebuilding is occurring at the single-species level. Considering 12 assessed stocks in the Gulf of Maine (including Georges Bank), five started to rebuild in the 1980s or 1990s following sustained reductions in fishing mortality $(F)$. Two flounder species started to rebuild in the 1990s, but were reduced again when $F$ crept back up. For two others (Atlantic cod and white hake) $F$ was not reduced until the 2000s and rebuilding has just begun. Finally, $F$ on three other species increased, as they became targets of new fisheries and their abundance declined. Thus stock rebuilding has been occurring for the past two decades, which may explain the monotonic changes in some community metrics. However, rebuilding started at different times; for some species it has not been sustained, while others have been targets of increased exploitation. This 
asynchronous rebuilding may explain why we do not yet see increases in community diversity.

By contrast, among the 10 assessed stocks in the North Sea, three started to rebuild in the 1980s or 1990s following sustained reductions in fishing mortality $(F)$. Among these, only haddock remains sustainably exploited and at full reproductive capacity since then; saithe started to rebuild in the 1980s, but peaked in 2005 and has decreased since then, as fishing mortality increased between 2004 and 2009; and herring went up and down, perhaps more in response to environmental forcing than fishing mortality (Appendix B). Norway pout (Trisopteris esmarkii) $F$ started decreasing early (1985), but the stock did not rebuild until recently. For six others (including cod and plaice), $F$ was not reduced until the 2000s and rebuilding has just begun. Thus stock rebuilding has been occurring mostly over the last decade, which may explain why most community metrics did not yet even start to change.

\section{Rebuilding in real communities}

How do real communities rebuild when fishing pressure is reduced and/or selectivity is decreased? Some of the metrics, such as biomass and mean size, varied little over the durations of the trawl surveys, suggesting that they are fairly conservative metrics. The size spectra have minor peaks but otherwise appear to be conservative properties of the community despite considerable variation in individual species (Murawski and Idoine 1992). On Georges Bank, changes in the community metrics were gradual and partly confirm what we had expected based on model simulations. The increase in biomass reflects an increase in numerical abundance, not an expansion of the age structure and corresponding increase in mean size. The increase in biomass over the entire time period is also consistent with the observed increase in pelagic productivity (Steele et al. 2007).

In the North Sea, none of the metrics showed a trend in the rebuilding direction, except geometric mean abundance, and size diversity in the last stanza. The former increased because many species increased in abundance, including the most dominant ones, so that evenness decreased further. Of the 26 species with a significant increasing trend in the North Sea, most are small-sized planktivores or benthivores; several are flatfish. The lack of response by the North Sea community to the reduction in fishing intensity can be ascribed to important changes in the environment, of which we see the effects in the two latter time stanzas. The 1988 regime shift appears to have favored small pelagic species (Reid et al. 2001), and can account for the increase in total abundance and decrease in mean size. Conversely the regime shift in the late 1990s was detrimental to pelagic planktivores. An analysis of trends by functional groups suggests that changes in the North Sea fish community propagated mostly from the bottom up, not from the top down (Rochet et al., in press).

\section{Rebuilding model communities}

In theory, community structure can be rebuilt when fishing pressure ceases, but it may take a long time. In simulations with LeMans, most metrics started to respond to a change in fishing pressure after five years, but few were restored to their unfished levels after 25 years. The highly depleted species, which tended to be the largest, increased very slowly to a small percentage of their unfished biomass after 25 years. In contrast, the smaller species increased rapidly to levels that exceeded their initial unfished biomass because of reduced predation. As a consequence, the predator-prey dynamics were altered, causing hysteresis in community rebuilding. On Georges Bank, biomass recovered after five years to its unfished level, suggesting that biomass is a conservative property of the community. In contrast, the response times were longer for the North Sea, because one of the dominant species, herring, recovered very slowly.

The size-based model, LeMans, was used to isolate the effects of fishing and predation on the community metrics. LeMans omits several mechanisms that may also influence community dynamics. The size-based predation incorporated in LeMans does not account for predation by clupeids on the eggs and larvae of cod (Minto and Worm 2012). This deterministic model does not incorporate environmental forcing or stochastic recruitment events that dominate the dynamics of particular species. Despite these omissions, LeMans serves our purpose of making qualitative predictions.

\section{Differences in rebuilding rates}

Why does the Georges Bank fish community appear to be rebuilding while the North Sea does not? Several complementary hypotheses may explain the difference between the two communities: (1) environmental effects; (2) the communities were different to start with; (3) time lags; and (4) a combination.

1) There has been environmental change on Georges Bank, although it was more gradual than in the North Sea. Sea surface temperature anomalies have a range of $\pm 1^{\circ} \mathrm{C}$ over time, but with a smaller overall trend. Shifts in species composition of the plankton have been observed but have not been mechanistically linked to fish productivity (Ecosystem Assessment Program 2009). In contrast, North Sea waters warmed on average by $1^{\circ} \mathrm{C}$ per decade from 1977 to 2001 (Perry et al. 2005), with a marked step in 1987 (Kirby et al. 2007). The North Sea ecosystem may be more sensitive to environmental drivers because it is on the eastern side of the Atlantic basin, where it is more influenced by prevailing westerly weather patterns. Or the North Sea may be more sensitive to environmental forcing because its fish populations are more heavily depleted (Anderson et al. 2008), which leads to Hypothesis 2. 
2) The community metrics from Georges Bank and the North Sea were different to start with. Our simulation experiment demonstrated that one cannot turn Georges Bank into the North Sea or vice versa just by switching the contemporary fishing patterns. This difference in fish community structure may reflect fundamental differences in ecosystem characteristics. Per unit of primary production, the North Sea has a higher transfer efficiency of secondary production than Georges Bank, yet a similar efficiency of fish production (Table 1). North Sea fish production depends more on zooplankton than benthos, which may favor planktivorous fish (Heath 2005). By contrast, Georges Bank has stronger benthic-pelagic coupling, which favors benthic production and demersal benthivores (Steele et al. 2007).

Another explanation is that the differences in community structure result from exploitation histories before the surveys started: the ghost of fisheries past. Based on fish remains in archaeological sites, it seems that intensification of marine fishing in England dated back as early as the 11th century (Barrett et al. 2004). By the 15th century, perceived shortages, whether due to overfishing or climate change, prompted European fishermen to seek other stocks. The marine ecosystem they encountered in the northwest Atlantic had a familiar suite of species but different structure and function (Bolster 2008). The fishery resources of Georges Bank were first tapped regularly between 1720 and 1740 by Massachusetts fishermen hand-lining for cod (German 1987). During the 19th century, New England fisheries expanded offshore as inshore stocks were depleted; the species sought expanded to include mackerel, halibut (Hippoglossus hippoglossus), and haddock.

Industrial fisheries have existed on Georges Bank and in the North Sea for over a century. Except for the world wars, fishing pressure appears to have been consistently high in the North Sea since the beginning of the 20th century (Poulsen et al. 2007, Pinnegar and Engelhard 2008, Thurstan et al. 2010). Total landings by the United Kingdom fleet between 1900 and 1980 fluctuated between 600 and $700 \mathrm{kt}$, which translates to approximately $1 \mathrm{t} \cdot \mathrm{km}^{-2} \cdot \mathrm{yr}^{-1}$. Long-term stock assessments suggest that fishing mortality on cod and whiting in the North Sea was as high in 1920-1940 as it was in $1945-1975(F \sim 0.5)$ and increased to $0.8-1$ $\mathrm{yr}^{-1}$ only recently, while fishing mortality on haddock has fluctuated around $0.8 \mathrm{yr}^{-1}$ since 1920 (Pope and Macer 1996). On Georges Bank, total landings increased from about $30 \mathrm{kt}$ at the turn of the century to $100 \mathrm{kt}$ after 1930 (Lange and Palmer 1985), which translates to $1-2 \mathrm{t} \cdot \mathrm{km}^{-2} \cdot \mathrm{yr}^{-1}$, suggesting that overall fishing removals have been of similar magnitude in the two ecosystems for almost a century.

A consequence of this intensive, long-term exploitation is a reduction in mean length of each species (Jennings et al. 1999). Large-sized fish in the North
Sea have been depleted for a longer time (Greenstreet and Hall 1996, Rijnsdorp et al. 1996) than on Georges Bank (Bolster 2008). Of 12 species common to both ecosystems, nine have larger asymptotic length $\left(L_{\infty}\right)$ on Georges Bank than in the North Sea, with a median ratio of 1.16:1. Moreover, the two ecosystems also differ in species composition, with more small and faster-growing species in the North Sea (Rochet et al. 2011: Fig. 1), which might also be a consequence of fishing (Daan et al. 2005). While both communities have been intensively fished for over a century, large-scale fisheries in the North Sea had a 500-year head start over Georges Bank.

3) There may be a delay between management regulations to reduce exploitation and community rebuilding. On Georges Bank there was a more rapid response to management interventions and clear signs of stock and community rebuilding. In contrast, substantial reductions in fishing mortality in the North Sea occurred more recently, stocks are just starting to rebuild, and there may be a time lag before the community rebuilds in turn. Daan et al. (2005) found that significant correlations between community metrics and exploitation rate were obtained only if time lags larger than six years were introduced. These delays are also consistent with response time in marine reserves, which might be as long as 15 years for large fish species (Molloy et al. 2009), and even more for community properties such as the size spectrum slope (McClanahan and Graham 2005). Simulations showed that community rebuilding may take a very long time, more than 25 years for most metrics, even when fishing ceased completely after the populations were heavily depleted. For the real communities the changes in fishing pressure were smaller and more gradual; we might therefore also expect the community responses to be small and gradual. In simulations with the fishing-mortality-by length vectors from the most recent time stanzas, some species remained depleted after 25 years, especially large ones like cod and saithe. On Georges Bank, some large predators, such as cod and white hake, remain depleted even as other species rebuild.

In summary, the difference in rebuilding rates between the North Sea and Georges Bank can be ascribed to several causes, which we cannot disentangle, and are probably combined. First, the communities were different to start with, and at least part of this difference can be ascribed to the earlier development of fisheries in the North Sea. Second, environmental changes were larger and more abrupt in the North Sea; the longer history of overfishing might also have made this community more sensitive to environmental fluctuations, with more smallsized and short-lived species. Third, the changes in fishing pressure were more gradual in the North Sea; on Georges Bank, the decrease in fishing intensity was accompanied by a decrease in fishing selectivity, which 
may have accelerated the rebuilding of the target species, and thus of the community itself. And fourth, community rebuilding in the North Sea is just starting, but, as predicted by Greenstreet et al. (2011), may take place over the next decade.

\section{Conclusions}

Community rebuilding is not simply the sum of singlespecies rebuilding plans. Species rebuild at different rates governed by their demographic parameters, which in turn alter the trophic interactions within the community. Long-lived predator species typically rebuild more slowly, while smaller species rebuild more quickly by virtue of faster intrinsic growth and predation release. The rebuilding community therefore has a different structure than the unexploited one, and the outcome may be unpredictable.

Aggregate numbers and biomass may be useful indicators of community rebuilding in the sense that they respond quickly to reduction in exploitation and may recover to pre-exploitation levels. Total biomass appears to be a conservative community metric, but a constant biomass can belie large shifts in species composition. In contrast, the metrics of size distribution and species diversity are more sensitive measures of community structure, but they rebuild slowly, if at all. Community metrics measured from contemporary trawl survey data reflect the cumulative effects of historical fisheries and recent overexploitation.

Simply decreasing fishing pressure is necessary for stock rebuilding, but may be insufficient for community rebuilding. We can expect time delays between reducing fishing pressure and the rebuilding of community metrics; in addition; the community response may be confounded by regime shifts in the environment. Selective fishing can delay community rebuilding, particularly if size-selective fisheries target the larger species that are slow to rebuild. Species-selective fisheries could be part of the problem if they amplify the imbalance in species composition as the community rebuilds, or they could be part of the solution if fastergrowing species are targeted while allowing the slowgrowing species to rebuild.

Ultimately, the need to rebuild communities depends on how society values biodiversity. If stocks rebuild within a community with different proportions of species that perform the same ecological functions, the ecological integrity of the system may be maintained, but fishermen would have to adapt to a different species mix. The ecosystem approach to fisheries management will need to articulate what level of community rebuilding is desirable and what level is attainable given past levels of depletion.

\section{ACKNOWLEDGMENTS}

We thank Jason Link for providing survey and catch data from Georges Bank. Henrik Gislason, Michael Fogarty, and an anonymous reviewer made useful comments on an earlier draft. J. Collie acknowledges NSF award OCE0814592. Marie-
Joëlle Rochet received financial support from the Pew Charitable Trusts. The opinions expressed are those of the authors and do not necessarily reflect the views of funding agencies.

\section{Literature Cited}

Andersen, K. H., and M. Pedersen. 2010. Damped trophic cascades driven by fishing in model marine ecosystems. Proceedings of the Royal Society B 277:795-802.

Andersen, K. H., and J. C. Rice. 2010. Direct and indirect community effects of rebuilding plans. ICES Journal of Marine Science 67:1980-1988.

Anderson, C. N., C.-H. Hsieh, S. A. Sandin, R. Hewitt, A. Hollowed, J. Beddington, R. M. May, and G. Sugihara. 2008. Why fishing magnifies fluctuations in fish abundance. Nature 452:835-839.

Auster, P. J., and J. S. Link. 2009. Compensation and recovery of feeding guilds in a northwest Atlantic shelf fish community. Marine Ecology Progress Series 382:163-172.

Barrett, J. H., A. M. Locker, and C. M. Roberts. 2004. The origins of intensive marine fishing in medieval Europe: the English evidence. Proceedings of the Royal Society B 271:2417-2421.

Barrett, N. S., G. J. Edgar, C. D. Buxton, and M. Haddon. 2007. Changes in fish assemblages following 10 years of protection in Tasmanian marine protected areas. Journal of Experimental Marine Biology and Ecology 345:141-157.

Beaugrand, G. 2004. The North Sea regime shift: evidence, causes, mechanisms and consequences. Progress in Oceanography 60:245-262.

Blanchard, J. L., N. K. Dulvy, S. Jennings, J. R. Ellis, J. K. Pinnegar, A. Tidd, and L. T. Kell. 2005. Do climate and fishing influence size-based indicators of Celtic Sea fish community structure? ICES Journal of Marine Science 62:405-411.

Bolster, W. J. 2008. Putting the ocean in Atlantic history: maritime communities and marine ecology in the northwest Atlantic, 1500-1800. American Historical Review 113:19-47.

Claudet, J., et al. 2010. Marine reserves: Fish life history and ecological traits matter. Ecological Applications 20:830-839.

Claudet, J., D. Pelletier, J.-Y. Jouvenel, F. Bachet, and R. Galzin. 2006. Assessing the effects of marine protected area (MPA) on a reef fish assemblage in a northwestern Mediterranean marine reserve: identifying community-based indicators. Biological Conservation 130:349-369.

Collie, J. S., A. D. Wood, and H. Perry Jeffries. 2008. Longterm shifts in the species composition of a coastal fish community. Canadian Journal of Fisheries and Aquatic Sciences 65:1352-1365.

Cotter, J., P. Petitgas, A. Abella, P. Apostolaki, B. Mesnil, C.-Y. Politou, J. Rivoirard, M. J. Rochet, M. T. Spedicato, V. M. Trenkel, and M. Woillez. 2009. Towards an ecosystem approach to fisheries management (EAFM) when trawl surveys provide the main source of information. Aquatic Living Resources 22:243-254.

Daan, N., H. Gislason, J. G. Pope, and J. Rice. 2005. Changes in the North Sea fish community: evidence of indirect effects of fishing? ICES Journal of Marine Science 62:177-188.

Ecosystem Assessment Program (EcoAP). 2009. Ecosystem status report for the northeast U.S. continental shelf large marine ecosystem. Reference Document 09-11. Northeast Fisheries Science Center, Woods Hole, Massachusetts, USA. Eisma, D. 1987. The North Sea: an overview. Philosophical Transactions of the Royal Society B 316:461-485.

Fogarty, M. J., and S. A. Murawski. 1998. Large-scale disturbance and the structure of marine systems: fishing impacts on Georges Banks. Ecological Applications 8:S6S22.

Fraser, H. M., S. P. R. Greenstreet, and G. J. Piet. 2007. Taking account of catchability in groundfish survey trawls: implica- 
tions for estimating demersal fish biomass. ICES Journal of Marine Science 64:1800-1819.

Genner, M. J., D. W. Sims, V. J. Wearmouth, E. J. Southall, A. J. Southward, P. A. Henderson, and S. J. Hawkins. 2004. Regional climatic warming drives long-term community changes of British marine fish. Proceedings of the Royal Society B 271:655-661.

German, A. W. 1987. History of the early fisheries: 1720-1930. Pages 409-424 in R. H. Backus and D. W. Bourne, editors. Georges Bank. MIT Press, Cambridge, Massachusetts, USA

Gislason, H., M. Sinclair, K. Sainsbury, and R. O' Boyle. 2000. Symposium overview: incorporating ecosystem objectives within fisheries management. ICES Journal of Marine Science 57:468-475.

Greenstreet, S. P. R., and S. J. Hall. 1996. Fishing and the ground-fish assemblage structure in the north-western North Sea: an analysis of long-term and spatial trends. Journal of Animal Ecology 65:577-598.

Greenstreet, S. P. R., S. I. Rogers, J. C. Rice, G. J. Piet, E. J. Guirey, H. M. Fraser, and R. J. Fryer. 2011. Development of the EcoQO for the North Sea fish community. ICES Journal of Marine Science 68:1-11.

Guidetti, P., S. Bussotti, and F. Boero. 2005. Evaluating the effects of protection on fish predators and sea urchins in shallow artificial rocky habitats: a case study in the northern Adriatic Sea. Marine Environmental Research 59:333-348.

Hall, M. A., D. L. Alverson, and K. I. Metuzals. 2000. Bycatch: problems and solutions. Marine Pollution Bulletin 41:204-219.

Hall, S. J. 1999. The effects of fishing on marine ecosystems and communities. Blackwell Science, Oxford, UK.

Hall, S. J., J. S. Collie, D. E. Duplisea, S. Jennings, M. Bravington, and J. Link. 2006. A length-based multispecies model for evaluating community responses to fishing. Canadian Journal of Fisheries and Aquatic Sciences 63:1344-1359.

Heath, M. R. 2005. Changes in the structure and function of the North Sea fish foodweb, 1973-2000, and the impacts of fishing and climate. ICES Journal of Marine Science 62:847868.

Heath, M. R., and D. J. Beare. 2008. New primary production in northwest European shelf seas, 1960-2003. Marine Ecology Progress Series 363:183-203.

ICES. 1996. Manual for the International Bottom Trawl Surveys. Addendum to ICES C.M. 1996/H:1. ICES, Copenhagen, Denmark.

ICES. 2008. Report of the working group on ecosystem effects of fishing activities (WGECO) May 6-13 2008, Copenhagen, Denmark. ICES CM 2008/ACOM:41. ICES, Copenhagen, Denmark.

Jennings, S. 2007. Reporting and advising on the effects of fishing. Fish and Fisheries 8:269-276.

Jennings, S., S. P. R. Greenstreet, and J. D. Reynolds. 1999. Structural change in an exploited fish community: a consequence of differential fishing effects on species with contrasting life histories. Journal of Animal Ecology 68:617627.

Jouffre, D., M. F. Borges, A. Bundy, M. Coll, I. Diallo, E. A. Fulton, J. Guitton, P. Labrosse, K. O. M. Abdellah, B. Masumbuko, and D. Thiao. 2010. Estimating EAF indicators from scientific trawl surveys: theoretical and practical concerns. ICES Journal of Marine Science 67:796-806.

Kempf, A., G. E. Dingsør, G. Huse, M. Vinther, J. Floeter, and A. Temming. 2010. The importance of predator-prey overlap: predicting North Sea cod recovery with a multispecies assessment model. ICES Journal of Marine Science 67:1989-1997.

Kirby, R. R., G. Beaugrand, J. A. Lindley, A. J. Richardson, M. Edwards, and P. C. Reid. 2007. Climate effects and benthic-pelagic coupling in the North Sea. Marine Ecology Progress Series 330:31-38.

Kramer, K. L., and K. L. J. Heck. 2007. Top-down trophic shifts in Florida Keys patch reef marine protected areas. Marine Ecology Progress Series 349:111-123.

Lange, A. M. T., and J. E. Palmer. 1985. USA historical catch data, 1904-82, for major Georges Bank fisheries. NOAA Technical Memorandum NMFS-F/NEC-39.

Link, J., A. Bundy, W. J. Overholtz, N. L. Shackell, J. Manderson, D. E. Duplisea, J. Hare, M. Koen-Alonso, and K. D. Friedland. 2011. Ecosystem-based fisheries management in the Northwest Atlantic. Fish and Fisheries 12:152170.

Link, J. S., C. A. Griswold, E. M. Methratta, and J. Gunnard. 2006. Documentation for the Energy Modeling and Analysis eXercise (EMAX). Reference Document 615, Northeast Fisheries Science Center, Woods Hole, Massachusetts, USA.

McClanahan, T. R., and N. A. J. Graham. 2005. Recovery trajectories of coral reef fish assemblages within Kenyan marine protected areas. Marine Ecology Progress Series 294:241-248

Minto, C., and B. Worm. 2012. Interactions between small pelagic fish and young cod across the North Atlantic. Ecology 93:2139-2154.

Molloy, P. P., I. B. McLean, and I. M. Côté. 2009. Effects of marine reserve age on fish populations: a global metaanalysis. Journal of Applied Ecology 46:743-751.

Murawski, S. A. 2000. Definitions of overfishing from an ecosystem perspective. ICES Journal of Marine Science 57:649-658.

Murawski, S. A., and J. S. Idoine. 1992. Multispecies size composition: a conservative property of exploited fishery systems? Journal of Northwest Atlantic Fishery Science 14:79-85.

Murawski, S. A., J. H. Steele, P. Taylor, M. J. Fogarty, M. P. Sissenwine, M. Ford, and C. Suchman. 2010. Why compare marine ecosystems? ICES Journal of Marine Science 67:1-9.

National Research Council. 1995. Understanding marine biodiversity. National Academy Press, Washington, D.C., USA.

Northeast Fisheries Science Center. 2010. Commercial fisheries database/landings, 1963-2009. NOAA Fisheries, Woods Hole, Massachusetts, USA.

Nye, J. A., J. S. Link, J. A. Hare, and W. J. Overholtz. 2009. Changing spatial distribution of fish stocks in relation to climate and population size within the Northeast US continental shelf. Marine Ecology Progress Series 393:111129.

OSPAR Commission. 2000. Quality status report 2000, Region II-Greater North Sea. OSPAR Commission, London, UK.

Palmer, M. A., R. F. Ambrose, and N. LeRoy Poff. 1997. Ecological theory and community restoration ecology. Restoration Ecology 5:291-300.

Palumbi, S. R., P. A. Sandifer, J. D. Allan, M. W. Beck, D. G. Fautin, M. J. Fogarty, B. S. Halpern, L. S. Incze, J.-A. Leong, E. Norse, J. J. Stachowicz, and D. H. Wall. 2009. Managing for ocean biodiversity to sustain marine ecosystem services. Frontiers in Ecology and the Environment 7:204211.

Parker, K. R., and J. A. Wiens. 2005. Assessing recovery following environmental accidents: environmental variation, ecological assumptions, and strategies. Ecological Applications 15:2037-2051.

Perry, A. L., P. J. Low, J. R. Ellis, and J. D. Reynolds. 2005. Climate change and distribution shifts in marine fishes. Science 308:1912-1915.

Piet, G. J., R. Van Hal, and S. P. R. Greenstreet. 2009. Modelling the direct impact of bottom trawling on the North Sea fish community to derive estimates of fishing mortality 
for non-target fish species. ICES Journal of Marine Science 66:1985-1998.

Pinnegar, J. K., and G. H. Engelhard. 2008. The 'shifting baseline' phenomenon: a global perspective. Reviews in Fish Biology and Fisheries 18:1-16.

Planque, B., J. M. Fromentin, P. Cury, K. F. Drinkwater, S. Jennings, R. I. Perry, and S. Kifani. 2010. How does fishing alter marine populations and ecosystems sensitivity to climate? Journal of Marine Systems 79:403-417.

Pope, J. G., and C. T. Macer. 1996. An evaluation of the stock structure of North Sea cod, haddock, and whiting since 1920, together with a consideration of the impacts of fisheries and predation effects on their biomass and recruitment. ICES Journal of Marine Science 53:1157-1169.

Poulsen, R. T., A. B. Cooper, P. Holm, and B. R. MacKenzie. 2007. An abundance estimate of ling (Molva molva) and cod (Gadus morhua) in the Skagerrak and the northeastern North Sea, 1872. Fisheries Research 87:196-207.

Quinn, T. J., and R. B. Deriso. 1999. Quantitative fish dynamics. Oxford University Press, New York, New York, USA.

Reid, P. C., M. F. Borges, and E. Svendsen. 2001. A regime shift in the North Sea circa 1988 linked to changes in the North Sea horse mackerel fishery. Fisheries Research 50:163171.

Rijnsdorp, A. D., P. I. van Leeuwen, N. Daan, and H. J. L. Heessen. 1996. Changes in abundance of demersal fish species in the North Sea between 1906-1909 and 1990-1995. ICES Journal of Marine Science 53:1054-1062.

Rius, M., and M. Zabala. 2008. Are marine protected areas useful for the recovery of the Mediterranean mussel populations? Aquatic Conservation: Marine and Freshwater Ecosystems 18:527-540.

Rochet, M. J., and E. Benoit. 2012. Fishing destabilizes the biomass flow in the marine size spectrum. Proceedings of the Royal Society B 279:284-292.

Rochet, M. J., J. S. Collie, S. Jennings, and S. J. Hall. 2011. Does selective fishing conserve community biodiversity? Predictions from a length-based multispecies model. Canadian Journal of Fisheries and Aquatic Sciences 68:469-486.

Rochet, M. J., J. S. Collie, and V. M. Trenkel. In press. How do fishing and environmental effects propagate among and within functional groups? Bulletin of Marine Science.

Rochet, M. J., and V. M. Trenkel. 2003. Which community indicators can measure the impact of fishing? a review and proposals. Canadian Journal of Fisheries and Aquatic Sciences 60:86-99.

Rochet, M. J., et al. 2010. Do changes in environmental pressures impact marine communities? An empirical assessment. Journal of Applied Ecology 47:741-750.
Shackell, N. L., A. Bundy, J. A. Nye, and J. S. Link. 2012. Common large-scale responses to climate and fishing across Northwest Atlantic ecosystems. ICES Journal of Marine Science 69:151-162.

Sissenwine, M. P., E. B. Cohen, and M. D. Grosslein. 1984. Structure of the Georges Bank ecosystem. Rapport et ProcesVerbaux Conseil International pour L'exploration de la Mer 183:243-254.

Steele, J. H., J. S. Collie, J. J. Bisagni, D. J. Gifford, M. J. Fogarty, J. S. Link, B. K. Sullivan, M. E. Sieracki, A. R. Beet, D. G. Mountain, E. G. Durbin, D. Palka, and W. T. Stockhausen. 2007. Balancing end-to-end budgets of the Georges Bank ecosystem. Progress in Oceanography 74:423448.

Stobart, B., R. M. Warwick, C. González, S. Mallol, D. Díaz, O. Reñones, and R. Goñi. 2009. Long-term and spillover effects of a marine protected area on an exploited fish community. Marine Ecology Progress Series 384:47-60.

Suding, K. N. 2011. Toward an era of restoration in ecology: successes, failures, and opportunities ahead. Annual Review of Ecology, Evolution, and Systematics 42:465-487.

Thurstan, R. H., S. Brockington, and C. M. Roberts. 2010. The effects of 118 years of industrial fishing on UK bottom trawl fisheries. Nature Communications 1:15. http://dx.doi: doi: 10 . 1038/ncomms 1013

United Nations. 1993. Convention on biological biodiversity. United Nations Treaty Series 1760:143-382.

Walters, C. J., R. Hilborn, and V. Christensen. 2008. Surplus production dynamics in declining and recovering fish populations. Canadian Journal of Fisheries and Aquatic Sciences 65:2536-2551.

Watson, D. L., M. J. Anderson, G. A. Kendrick, K. Nardi, and E. S. Harvey. 2009. Effects of protection from fishing on the lengths of targeted and non-targeted fish species at the Houtman Abrolhos Islands, Western Australia. Marine Ecology Progress Series 384:241-249.

Wilson, S. K., R. Fisher, M. S. Pratchett, N. A. J. Graham, N. K. Dulvy, R. A. Turner, A. Cakacaka, and N. V. Polunin. 2010. Habitat degradation and fishing effects on the size structure of coral reef fish communities. Ecological Applications 20:442-451.

Worm, B., et al. 2009. Rebuilding global fisheries. Science 325:578-585.

Zhou, S., A. D. M. Smith, A. E. Punt, A. J. Richardson, M. Gibbs, E. A. Fulton, S. Pascoe, C. Bulman, P. Bayliss, and K. Sainsbury. 2010. Ecosystem-based fisheries management requires a change to the selective fishing philosophy. Proceedings of the National Academy of Sciences USA 107:9485-9488.

\title{
Supplemental Material
}

\author{
Appendix A \\ Summary of changes in drivers on Georges Bank (Ecological Archives A023-019-A1).

\section{Appendix B} \\ Summary of changes in drivers in the North Sea (Ecological Archives A023-019-A2).
}

\section{Appendix C}

Lists of species selected from the trawl surveys and used in the analyses (Ecological Archives A023-019-A3). 